NBER WORKING PAPER SERIES

\title{
DO STRONGER PATENTS INDUCE MORE INNOVATION? EVIDENCE FROM THE 1998 JAPANESE PATENT LAW REFORMS
}

\author{
Mariko Sakakibara \\ Lee Branstetter \\ Working Paper 7066 \\ http://www.nber.org/papers/w7066
NATIONAL BUREAU OF ECONOMIC RESEARCH
1050 Massachusetts Avenue
Cambridge, MA 02138
April 1999

\begin{abstract}
Presented at the NBER Conference "The Patent System and Innovation" funded by the Alfred P. Sloan Foundation via a grant to the NBER Project on Industrial Technology and Productivity.Sakakibara gratefully acknowledges the financial support of the Center for International Business Education and Research at the UCLA Anderson Graduate School of Management. Sakakibara would like to thank officials at the Japanese Patent Office, especially Masafumi Yamamoto and Shunichi Doi for detailed information on the Japanese patent systems, Takao Oogiya for information on patenting by Japanese firms, and Yoshisue Tsunoda and Michiko Tanaka for their help in arranging interviews with Japanese companies. Sakakibara is also grateful to the general managers of intellectual property departments at 10 major Japanese companies for sharing their insights. Akinori Yamaguchi and Tsuyoshi Kakita at the Japan Patent Information Organization provided us with detailed Japanese patent data. In addition, we would like to thank Wesley Cohen, Robert Feenstra, Nancy Gallini, Charles Jones, Marvin Lieberman, Hugh Patrick, Mark Schankerman, Hideki Yamawaki, and participants in the Summer 1998 NBER Patent Systems and Innovation pre-conference, the January 1999 NBER Patent Systems and Innovation Conference, and the February 1999 NBER Japan Project Conference for helpful discussions and comments. Branstetter wishes to thank Professor Yosuke Okada of Shinshu University for discussions which inspired this research project, and for providing valuable information about the evolution of the Japanese patent system. Kaoru Nabeshima, Heather Berry, and Tatsuo Ushijima provided excellent research assistance. The views expressed in this paper are those of the authors and do not reflect those of the National Bureau of Economic Research.
\end{abstract}

( 1999 by Mariko Sakakibara and Lee Branstetter. All rights reserved. Short sections of text, not to exceed two paragraphs, may be quoted without explicit permission provided that full credit, including ${ }^{\circledR}$ notice, is given to the source. 
Do Stronger Patents Induce More Innovation?

Evidence from the 1988 Japanese Patent Law Reforms

Mariko Sakakibara and Lee Branstetter

NBER Working Paper No. 7066

April 1999

\section{ABSTRACT}

Does an expansion of patent scope induce more innovative effort by firms? This article provides evidence on this question by examining firm responses to the Japanese patent reforms of 1988. Interviews with practitioners suggest the reforms significantly expanded the scope of patent rights in Japan, but that the average response in terms of additional R\&D effort and innovative output was quite modest. Interviews also suggest that firm organizational structure is an important determinant of the level of response. Econometric analysis using Japanese and U.S. patent data on 307 Japanese firms confirms that the magnitude of the response is quite small.

Mariko Sakakibara

Anderson Graduate School of Management University of California, Los Angeles

110 Westwood Plaza

Los Angeles, CA 90095-1481

mariko.sakakibara@anderson.ucla.edu
Lee Branstetter

Department of Economics

University of California, Davis

Davis, CA 95616

and NBER

branstet@ucdavis.edu 


\section{Introduction}

Since Nordhaus' early contribution (Nordhaus, 1969, 1972), economic theorists have undertaken extensive analysis of the problem of optimal patent design. Theorists have long recognized the tradeoffs inherent in the patent system - a system which creates static losses (by conferring upon innovators temporary monopoly power) in order to realize dynamic social gains by inducing greater innovative effort.

Within policy circles, the debate surrounding intellectual property rights design and enforcement has also increasingly come to the forefront. As has been widely noted, legal and procedural reforms in the U.S. in the early 1980s provided stronger protection to holders of existing patents, reflecting a shift in the U.S. policy consensus in favor of stronger intellectual property rights protection. This policy shift then took on an international dimension as several consecutive U.S. administrations placed intellectual property rights at the center of the U.S. agenda in bilateral and multilateral trade negotiations. ${ }^{1}$ Since the early 1980s, the U.S. has repeatedly sought to cajole or coerce its trading partners into significantly strengthening their own intellectual property rights regimes, bringing them more in line with the new U.S. model.

However, neither the expanding theoretical literature on patent design nor the international policy debate has been sufficiently guided by empirical work. ${ }^{2}$ Much recent theoretical work explicitly assumes that $R \& D$ performing firms are quite responsive to subtle changes in patent design. The U.S. position in the international fight over intellectual property rights is based on the proposition that the additional innovation induced by stronger patent systems is so substantial that the net social impact of a strengthening of intellectual property rights abroad will be positive. These propositions are empirically testable, yet the empirical evidence underlining these propositions ranges from sketchy to nonexistent.

Does an expansion of the scope of patent rights really induce more innovative effort? Our paper provides badly needed empirical evidence on this question by analyzing the response of Japanese firms to the Japanese patent reforms of 1987, enacted in January 1988 (hereafter the 1988 reforms or "patent reform"). For reasons which we document in the paper, this Japanese reform provides an unusually clean 
"natural experiment." ${ }^{3}$ Furthermore, this policy reform was undertaken in a country with a large number of R\&D-intensive firms that had reached the global "technology frontier" by the time the reforms were enacted. ${ }^{4}$ Thus, we have micro-level data on the R\&D investment and patenting of a large number of firms both prior to and after the enactment of reforms. Finally, Japanese firms are not only aggressive about seeking patent protection at home, but they are also aggressive in patenting in the U.S., receiving approximately $25 \%$ of all patents granted by the U.S. Patent and Trademark Office (U.S. PTO). There was no similar change in U.S. patent law at the time of the 1988 reforms. Because we possess two parallel patent series for our sample firms, we may be able to identify more precisely just what the impact of the patent reforms was on innovative output.

We show that the 1988 patent reforms in Japan expanded the scope of patent protection, as defined by the theoretical literature on patent design, based on interviews with practitioners. Interview results also suggest that organizational setting has an effect on firms' response to changes in patent systems. Empirically analyzing data on 307 Japanese firms during the period 1980 to 1994, we find little evidence that this expansion of patent scope induced additional $R \& D$ effort by Japanese firms. We also examine whether or not the Japanese patent reform resulted in additional innovative output by examining firm patenting in the U.S. and Japan. We find some evidence consistent with the hypothesis that innovative output increased. However, only a portion of this increase can be reasonably attributed to the effects of patent reform. Taken together, the empirical evidence suggests that firm responsiveness to even significant changes in patent design is limited. This has important implications for both the current policy debate and the theoretical literature, which we discuss in our conclusion.

This article is organized as follows. Section 2 explains the pre-reform Japanese patent system. Section 3 describes the 1988 Japanese patent system reforms. This section also explains why these reforms can be considered an "exogenous" policy change. Section 4 discusses the perceptions of the effects of the reforms by practitioners and demonstrates that patent reform effectively expanded the scope of patent protection. Section 5 establishes the linkage between the 1988 reforms and theoretical literature, and 
introduces a model which summarizes the expected effect of the 1988 reforms on innovation. Section 6 examines the impact of patent reform on Japanese firms at the aggregated level. Section 7 empirically analyzes the impact of patent reform on R\&D spending. Section 8 examines the effect of the patent reforms on Japanese firms' patenting in Japan and the U.S., and section 9 concludes.

\section{The Japanese patent system before the 1988 reforms}

Japanese and American patent examiners followed similar standards of what constituted a patentable invention. A major difference between the two patent systems concerned the scope of a patent. ${ }^{5}$ A claim defines the subject matter which an applicant regards as his or her invention. Japanese patents covered a single, independent claim - meaning that one novel advance was permitted per patent. In contrast, American and European patents often listed multiple, independently valid claims. The Japanese single-claim system (or the "head claim system") meant that, compared with other nations, many more Japanese patents had to be filed to cover the same technology. This difference led to a much greater number of patent applications in Japan than in other countries.

It was also argued that the scope of each claim tended to be narrower in Japan than in the U.S. A patent in the U.S. could claim protection for broad classes of a product, whereas in Japan only specific cases of the product that had been proven in practice could be patented. For example, if a new material could conceivably contain $10 \%$ to $50 \%$ of a certain ingredient, the U.S. patent could specify this range; in Japan the patent covered only the specific percentage that the inventor had used. ${ }^{6}$ As each patent was so thinly defined under the Japanese patent system, ${ }^{7}$ some critics even called it the sashimi system, after the Japanese sliced fish delicacy. ${ }^{8}$

\section{The 1988 reforms}

From the single-claim system to the "improved" multiple-claim system. Before 1976, Japanese patent law allowed only one independent, single claim to be included in an invention. A 1976 amendment 
to the patent law allowed the inclusion of multiple dependent claims, which defined the technical ways to implement an independent claim, in the same patent application. This amendment, however, did not substantially change the number of claims included in a patent.

In contrast, the 1988 reforms significantly expanded the extent to which multiple claims could be included in one patent. Patent applicants can now define the coverage of an invention with multiple claims, and those claims can be either independent of or dependent on other claims. In addition, the extent to which related inventions could be included in a single patent was dramatically expanded by the new law. For example, in patenting chemical compounds, both the final chemical compound and the intermediate products generated in its manufacture can be covered by one patent (Niihara ed., 1987). Patent experts contend that, after the 1988 reforms, the scope of invention covered by a single patent application equaled or even exceeded that conferred by the U.S. and European patent systems (Okamoto et. al., 1996). The consequences of expansion of patent scope under these reforms will be our primary empirical focus in this paper.

Patent term restoration for pharmaceuticals. The 1988 reforms also provided patent term restoration of up to five years for the period necessary for drug safety and efficacy examination if the patented invention could not be implemented for more than two years due to delays in the examination process. This amounted to an effective extension of the length of patent rights in the pharmaceutical industry. Our data set includes all of the important participants in the Japanese pharmaceutical industry, allowing us, in principle, to explore the innovation-inducing effects of increased patent length as well as increased patent scope. ${ }^{9}$

Motives of the series of reforms. When a patent system reform comes about primarily through the lobbying efforts of the system's primary beneficiaries, it is not clear that such a reform can be taken as exogenous. In the case of the 1988 reforms, much of the political impetus for change came, not from heavy domestic users of the patent system, such as Sony or NEC, but from Japan's trading partners - chiefly the U.S. The purpose of those reforms was to harmonize the Japanese patent system with that of other 
countries, and so was driven by motives largely exogenous to the wishes of Japanese firms.

Many of the reasons for American dissatisfaction with the pre-reform Japanese patent system are well illustrated by the case of Fusion Systems, which was made famous by a Harvard Business School case study. Fusion Systems was a small U.S. high-tech company which invented a microwave lamp in 1974. Fusion Systems sought patent protection in Japan for its invention, filing 20 patents in Japan by 1983. While 20 U.S.-style multi-claim patents might have been enough to secure Fusion Systems' intellectual property rights, the 20 single-claim patents the company filed in Japan left substantial "holes" in the intellectual product space it had sought to protect. Before Fusion Systems could correct this error, its chief competitor in the Japanese market, Mitsubishi Electric, exploited its mistake by filing 139 patents in closely related technologies - an example of a practice known as "patent flooding." After finding that Mitsubishi Electric's 139 patent applications had effectively prevented it from plugging the "holes" in its intellectual property protection, Fusion Systems appealed to USTR. ${ }^{10}$ Other U.S. firms with similar complaints put additional political pressure on the U.S. government to pressure the Japanese government for a stronger intellectual property rights regime. The major outcome was the introduction of the multi-claim system.

At the same time, the U.S. and other countries requested that Japan shorten the patent examination period. Due to a severe backlog, the average examination period (from the request of the examination ${ }^{11}$ to the end of the examination) reached 36 months in 1985. One cause of the delay was the very large number of patent applications filed by Japanese firms. The broadening of patent scope was expected to reduce the number of patent applications. Parallel to the 1988 reforms, the Japanese Patent Office asked the top 100 patenting companies, which account for $50 \%$ of the total patenting, to reduce the number of unnecessary and trivial patent applications in $1988 .^{12}$

\section{Expected results of the reform and the perception by practitioners}

The significance of the multi-claim system. In order to evaluate the expected and perceived outcomes of the 1988 reforms, we conducted a series of interviews in Japan in March - September, 1998. 
Six high-ranking officials at the Japanese Patent Office, general managers of intellectual property departments at 10 major Japanese companies in electronics, office equipment, pharmaceuticals, chemicals, and food industries, and three officers at the Japan Patent Information Organization (JAPIO), a quasigovernment organization which provides a Japanese patent electronic database, were interviewed.

Figure 1 about here

Figure 1 illustrates the effect the new multi-claim system, as perceived by company managers and Japanese Patent Office officers. The Xs in the center are inventions by a firm and each circle represents a claim. Let us assume this company invented a chip which is used for image processing. The Xs are the chip itself, and the processes used to make the chip. One circle represents a camera which contains this chip. Another circle represents a personal computer which includes this chip. The third circle might be a system which combines this chip, a camera, and a personal computer. The multi-claim system allows one patent to contain all of these claims. Thus, a firm tries to maximize the territory covered by these circles without tapping into claims associated with inventions by other firms. Under the single-claim system, a company can draw only one circle, resulting in much narrower scope of intellectual property protection.

Does the multi-claim system really matter? One might argue that before the 1988 reforms, innovators could duplicate the protection afforded by patents of greater scope by simply taking out multiple patents. ${ }^{13}$ This argument would be incorrect if (1) the multi-claim system substantially reduced the cost of a given level of patent protection, or (2) if the multi-claim system substantially improved the breadth of patent protection (meaning innovations that could not be completely protected under the old system could now receive full protection). Based on our interviews and on more objective data, we will argue that patent reform did indeed produce effects (1) and (2). The extent and relative strength of these two effects, of course, is difficult to calculate with precision, but we believe the effect of (2) is more substantial for reasons discussed below.

Before addressing these issues, however, we feel that it is important at the outset to dispel the 
widely held misconception that patents are neither important nor effective as instruments of appropriation of innovation in Japan. Strong evidence to the contrary is presented in the recent paper by Cohen et. al. (1998). The authors conduct a comprehensive survey of the R\&D managers of U.S. and Japanese R\&Dintensive firms. Firms' responses to these surveys suggest that Japanese firms regard patents as among the most effective instruments of appropriation of innovation. ${ }^{14}$ In striking contrast, U.S. firms' responses suggest that American firms find patents to be a much less effective means of protection than, for instance, trade secrecy. Likewise, when asked their most important reasons for patenting innovations, Japanese firms listed prevention of imitation, blocking similar innovation by rivals, and the prevention of lawsuits as the most important reasons for filing patents for both product innovations and process innovations. ${ }^{15}$

Financial implications of patent reform. The most obvious implications of patent reform, and the easiest to demonstrate quantitatively, are the reductions in private patenting costs to the firms. To put it simply, taking out multiple patents to protect a single idea under the "sashimi" system could prove quite costly. Examination fees and agent fees, which are several times higher than the actual examination fees, had to be incurred for each patent if multiple patents were filed to protect a single innovation. Multiple patenting per invention would also increase the cost of enforcing patent rights if patent infringement took place, since a lawsuit would have to be filed for each patent infringed. Many companies suggested in interviews that the multipleclaim system brought an opportunity to save patent related fees through the combination of multiple claims (and therefore multiple inventions) in one patent application, because a substantial portion of patent fees are incurred per patent, not per claim. ${ }^{16}$

As an illustration of the potential cost savings, we use the patent fee schedule as of 1996. Official fees including the filing fee and the examination fees are 105,300 yen per patent and 2,700 yen per claim. Okamoto (1996) estimates that the agent fees incurred in the processing of these patent documents (as explained later, some interviewed firms rely on agents to process as much as $70 \%$ of their patent applications) were 604,000 yen per patent. Finally, maintenance fees for the life of the patent, assuming the patent is registered at the fourth year from the filing, include 1,301,000 yen per patent and 132,300 yen 
per claim. Under this fee schedule, the total costs of protection for a patent is 2,010,300 yen per patent (denoted F, for the "fixed cost" of a patent) and 135,000 yen per claim (denoted V, for the "variable cost" of a claim).

In 1993, for example, the average number of claims per patent (denoted $\mathrm{N}$ ) is 3.77 . Under the 1996 fee schedule, the total cost for the life of a typical patent is $\mathrm{NV}+\mathrm{F}=2,519,250$ yen. Assuming that under the old system each claim has to be filed as an independent patent ${ }^{17}$, the total cost for the life of a patent to cover the same invention was $\mathrm{N}(\mathrm{V}+\mathrm{F})=8,087,781$ yen. The cost saving from the multi-claim system is $\Delta \mathrm{C}=\mathrm{N}(\mathrm{V}+\mathrm{F})-(\mathrm{NV}+\mathrm{F})=5,568,531$ yen, or a $68.9 \%$ cost saving. The number of the total patent applications in Japan in 1993 was 366,486, and so the total cost saving would be 2,041 billion yen or $\$ 17$ billion (using $\$ 1=120$ yen). This illustration suggests that the total cost savings could be quite substantial. $^{18}$

Admittedly, this sum is an upper bound. It overstates our case, as not all patents which are examined are granted, nor are maintenance fees paid on all patents. Nevertheless, given the fee structure, the potential costs savings are so large that they remain substantial even after more realistic adjustments are made. Assuming only $10 \%$ of filed patents are examined and maintained, for example, the total cost saving will still be 224 billion yen or $\$ 1.8$ billion. ${ }^{19}$

While the private benefits of cost reduction for a given amount of patent protection are clear, the social benefits are less so. A substantial reduction in the cost of patenting could lead firms to seek to protect lower quality ideas. Certainly, we might expect the "quality" of the marginal protected idea to decline with a large enough decline in cost. In fact, if the only real effect of patent reform was to reduce the private cost of patent protection, we would expect to observe firms "repackaging" the same number of ideas into fewer patents, thereby realizing cost savings, but we would not necessarily expect such a reform to induce additional innovative output.

Real expansion of intellectual property rights under patent reform. An alternative 
interpretation of these reforms is that, not only did they provide cost savings, but the advent of the multiclaim system really did generate an increase in the breadth of intellectual property protection. Whether this really happened or not is quite difficult to verify without detailed knowledge of changes in patent practice that occurred after reform. When we went to those individuals most knowledgeable about these changes Japanese Patent Office officials and the heads of intellectual property departments at major corporations they claimed that this increase in effective scope did occur.

In practice, the total protection afforded by multiple narrow patents fell short of the protection conferred by the new broader patents. All possible modifications to the original innovation were often not regarded by patent examiners as bona fide independent innovations. Interviewees suggested that, in practice, the "burden of proof" in establishing novelty was less stringent for a claim than for a patent. Some firm managers also said that the multi-claim system allowed firms to describe an invention in multiple dimensions, which increased the opportunities to demonstrate the novelty of the invention and, thus, actually increase the chance that a patent is granted. ${ }^{20}$

The multi-claim system allowed the patent applicant to define the invention in ways which made infringement easier to prove and prosecute under Japanese legal practice. This is an extremely important but rather complicated point, which is best illustrated by example. Fortunately, Hiraoka et. al. (1988) and Japan Patent Association (1988) provide many such examples. In the following case, a firm found that if chemical compounds A and B (both publicly known materials) were combined at a specific ratio with polyethylene, they significantly prevent the deterioration of polyethylene products. In filing a patent application for this invention, there were several alternative ways to describe it.

(1) An additive which consists of materials A and B, that prevents the deterioration of polyethylene (which emphasizes the product)

(2) A strengthened shaped polyethylene product which consists of materials A and B and polyethylene (which emphasizes the product)

(3) A method to produce strengthened shaped polyethylene products which is characterized by 
adding materials A and B to polyethylene (which emphasizes the production process)

After the 1988 reforms, (1), (2), and (3) could be included as separate claims in one patent. Under the old system, however, the inventor had to choose one claim from the above three to include in the patent application, since all three claims point to the same invention. If a patent including one of above claims was granted, subsequent patent applications by the same inventor which contained any of the remaining claims would be rejected on the grounds of not having met the "one invention, one patent" principle or the "unity" requirement. Subsequent patent applications by other inventors which contained any of these remaining claims would be rejected on the grounds of not having met the novelty requirement, as these overlapping claims point to essentially the same invention. This does not mean, however, that a patent with one claim protects the intellectual property space covered by the other closely related claims, because claims are narrowly interpreted under historical Japanese legal practice. If the inventor is granted a patent which includes (1), then the inventor would not be able to sue someone selling a shaped polyethylene product for infringement unless he/she could prove that the produce is the result of adding the protected additive to polyethylene. Similarly, if the inventor chooses to include (2) in a patent filing, then he/she could only sue a rival firm selling the protected additive for infringement if it can be proven that the additive will be used only for the production of the strengthened shaped product. Finally, in case the inventor chose to include (3), he/she would not be able to sue someone selling the additive for infringement unless he/she could prove that the additive would only be used for the patented method. In practice, these indirect infringement cases were very difficult to prove in court. The old system illustrated here might sound very strange to Western readers, but the philosophy behind it is that a claim should briefly and clearly define an invention, and so a claim (and a patent) can include only the essential features of an invention.

To sum up, the narrow interpretation of claims for purposes of determining infringement created a "commons" of intellectual product space around existing patent grants which no patent holder could effectively appropriate and within which any firm was free to operate. This situation changed with patent 
reform. Firms were now allowed to use claims "defensively." In addition to describing independent innovations, the claims could be used to "fill in" the traditional "commons," substantially strengthening the firms' scope of intellectual property rights. ${ }^{21}$ It is this sort of effect that the theoretical literature highlights in models of patent scope. To the extent that this effect was present in the wake of Japanese patent reform, examining the Japanese case will allow us to get some sense of how firms respond to such an expansion of patent scope.

Note, however, that this "defensive" use of overlapping claims is a very different use of the multiclaim system from that outlined in the preceding subsection. Here firms are not using the multiclaim system to repackage several independent ideas into one patent document so much as they are using overlapping claims to fill in the "no man's land" around a single invention. Interview evidence and quantitative firm-level evidence suggests that firms used the multi-claim system in both ways in different patents, so that both effects had an actual impact on Japanese firms' patenting practices.

Managerial implications of patent reform. Interview results of general managers of intellectual property departments showed interesting differences in the effects of the multi-claim system across firms. They indicated that the degree of change in firms' patenting behavior and the utilization of the new multiclaim system was strongly related to the degree to which patent-related tasks are conducted within the firm, and to the number of people in a company involved in patent processing. In one electronics company, for example, over the course of a single year 30 people in the intellectual property department engaged in producing 20,000 domestic patent applications as well as thousands of overseas patents. However, the generation of more than $70 \%$ of the actual patent documents, both for Japan and overseas filings, was contracted out to patent agents. For another company, the degree of outsourcing is more than $90 \%$. In situations such as these, where there is such a profound organizational disconnect between those in the firm (or outside the firm) dealing directly with the patent system, and those in the firm actually conducting $\mathrm{R} \& \mathrm{D}$, it is perhaps not surprising that the "feedback" from changes in the patent system to the conduct of $\mathrm{R} \& \mathrm{D}$ was muted and slowed. On the other hand, at one consumer electronics company, $70 \%$ of the patent 
application documents are drafted by the corporate $R \& D$ personnel actually producing the innovations. In such a context, the "feedback" from patenting changes to the conduct of R\&D is, not surprisingly, much stronger.

Some companies also admitted that the internal incentive structures worked, in some cases, to prevent $\mathrm{R} \& \mathrm{D}$ departments from responding to patent law changes. At one large diversified company, business units shared costs related to patent administration through the intellectual property division of the company's headquarters, with the cost allocation determined by the number of patent applications in previous years. Business units were not allowed to retain any "patent administration cost" savings if they filed fewer patents than in previous years, which deterred these business units from responding to patent law changes which were designed to reduce the number of patent filings. On the other hand, in some companies, the internal reward structure was changed, with greater emphasis placed on maximizing the number of claims rather than simply the number of patents.

Interviewees suggested that company-specific factors were likely to influence the degree of firm responsiveness to patent reforms, in addition to the aforementioned organizational factors. The degree of learning and the utilization of the new patent system in R\&D efforts also depended on the efforts of intellectual property departments. In many companies, commentaries and examples of the multiple-claim system were documented and circulated among $R \& D$ departments, which stimulated the thinking of engineers concerning how to utilize an invention in multiple ways. In some companies, a series of seminars were held to communicate the change in the patent system to researchers.

In the cases where the "feedback" from patent changes to R\&D conduct was strong, some corporate $\mathrm{R} \& \mathrm{D}$ managers reported that it had an impact on the manner in which researchers approached innovation. Some R\&D managers in the office equipment industry noted, for example, that R\&D personnel began to look for new/multiple applications of an innovation due to the multi-claim system. However, this response was far from unanimous. Many respondents claimed that neither the multi-claim system nor the effective extension of patent rights in the pharmaceutical industry had a significant impact on the nature or 
level of R\&D activity. ${ }^{22}$

Theorists in this literature typically assume that the "innovating unit," be it an individual or a firm, directly confronts and internalizes the incentives in the patent system. Our interviews drove home the reality that corporate $R \& D$ departments are embedded in larger organizations, and the feedback from changes in the patent system to their activity is anything but automatic. Organizational settings affect how innovations are turned to patents, and organizational settings vary across firm. We need to keep this reality in mind not only in interpreting our empirical results, but also in determining the lessons our study has for the next generation of theoretical models.

\section{Theoretical linkage between the 1988 reforms and R\&D}

The multi-claim system and the theoretical literature on patent scope. In this section, we establish a link between these institutional changes in Japan and the theoretical literature on patent scope. This requires that we briefly review this literature. However, due to space constraints, we will necessarily be selective and incomplete in our review.

In Nordhaus' original work, and in the famous exchange with Scherer that followed, emphasis was placed on the optimal length of a patent as a policy variable. ${ }^{23}$ In this setup with the assumption that patent protection allows patent recipients to fully command monopoly rents, the optimal length of a patent was found to be finite. Gilbert and Shapiro (1990) and Klemperer (1990) used more sophisticated modeling frameworks to consider both the optimal length and breadth of a patent. They found conditions under which a narrow but infinitely long patent is optimal, thereby demonstrating the importance of patent breadth, or scope, as an instrument of patent policy. Gilbert and Shapiro (1990) define the scope of patents as anything which increases the flow rate of the innovator's profits during the period of protection, whereas Klemperer (1990) defines it as the area of differentiated product space covered by a patent grant. Much theoretical work followed, including Gallini (1992) and Matutes et. al. (1996). Gallini (1992) defines the scope in terms of the cost of imitation, while and Scotchmer and Green (1990) define scope in terms of 
novelty. Finally, Matutes et. al.'s (1996) definition relates to the leniency of courts (and the patent office) in granting claims of innovation that are not fully developed.

We contend that the introduction of the "improved" multiple-claim system effectively expanded the scope of patent protection in Japan along a number of important dimensions stressed in the literature. The definitions used by Klemperer and Gallini fit especially well with the 1988 reforms, since the multi-claim system allows firms to include all possible applications and related inventions within a single patent grant. ${ }^{24}$ Thus the reform certainly increased the differentiated product space covered and the imitation costs.

On the other hand, there were some important dimensions of patent scope along which there was less strong evidence of change. The literature has also stressed the ex-post legal interpretation of patents in the courts vis-à-vis subsequent innovation as a dimension of patent scope. ${ }^{25}$ We have no direct evidence of any change in this ex-post interpretation of the scope of patent claims by the courts immediately after reform. ${ }^{26}$ Anecdotal evidence suggests a gradual turning of Japanese legal practice towards a more "propatent holder" position. Later, we will present circumstantial evidence consistent with this shift.

Furthermore, we believe that the presence of substantial change along some dimensions of patent scope and the apparent absence of substantial change along other dimensions is actually a useful feature of the data, as it allows us to separate out the partial effect on incentives for innovation of expansion of patent scope along some particular dimensions. On the other hand, we must acknowledge that the absence of expansion along other dimensions limits our conclusions. That is simply the nature of our natural experiment. Nevertheless, in the absence of any real empirical evidence on the responsiveness of firms to changes in patent design along any dimension, even a limited natural experiment is welcome.

Model. Having established that the broadening of patent scope in Japan "fits" with the theoretical treatment of expansion of patent scope along a number of important dimensions, we review the theoretical relationship between changes in patent scope, or length, and the optimal level of R\&D effort. We show that the first-order impact of an expansion of patent rights, both in scope and in length, on the level of $\mathrm{R} \& \mathrm{D}$ is positive. 
The particular framework that we use here borrows heavily from Denicolo (1996), which, in turn, is based on Lee and Wilde (1980). We consider a race for a patentable innovation between n symmetric firms. In this model, both the winner and losers of the patent race get positive profits in the post-innovation equilibrium. The length of the patent is finite, and after the patent has expired, both the winner and losers get the same positive profits. Each firm chooses its R\&D investment to maximize its expected profit. The $\mathrm{R} \& \mathrm{D}$ technology is "memoryless", i.e. a flow of expenditure $x_{i}$ yields a probability of discovery $h\left(x_{i}\right)$ per unit of time. Key assumptions in this model are that the equilibrium investment level, $x *$, the flow of profits accruing to the winner, $\pi_{W}$, and the flow of profits accruing to the non-innovating firms, $\pi_{L}$ are functions of the breadth of the patent, which can be denoted as $b$, and that $\pi_{W}{ }^{\prime}(b)>0$ and $\pi_{L}{ }^{\prime}(b) \leq 0$. We also assume a stability condition analogous to Lee and Wilde's. From these assumptions, we show that, even in a model of innovative competition among firms where the outcome of innovation is uncertain, an expansion of patent scope (and length) induces additional innovation. Appendix 1 shows the full description of the model.

This result, although general to a broad class of models, does not hold in every conceivable circumstance. Merges and Nelson (1994) discuss behavioral, historical, and technology-specific aspects to be considered for the evaluation of the effect. We also note that neither the model presented here, nor the simpler framework on which our empirical work is based consider sequential innovation. ${ }^{27}$ In this important, more recent branch of the theoretical literature, the impact of an expansion of patent scope can have either positive or negative effects on $R \& D$. A narrow patent scope might induce subsequent innovation because it encourages incremental innovation. On the other hand, a broad patent scope might induce subsequent innovation because a broad patent scope will force an innovator to disclose more technical knowledge, which can then be used by subsequent innovators. These conflicting effects are due to the dual roles played by patents, as instruments of diffusion and exclusion (Ordover, 1991). Even though theory may yield ambiguous predictions concerning the impact of patent scope, it is critically important for 
policy makers to know which effects predominate in practice. This is what we seek to estimate.

\section{Effects of the $\mathbf{1 9 8 8}$ reforms - results at the aggregated level}

Results from Japanese patent data at the aggregated level. A number of changes have been observed after the 1988 reforms at the aggregated level. Figure 2 shows the trend of patent applications in Japan in the postwar period. A vertical line is drawn in 1987, the end of the pre-reform period in order to highlight the changes after the 1988 reforms. Figure 2 shows that the growth rate of the number of patent applications has declined after 1988, though the actual number of patent filings is still increasing. In general, this pattern holds across technological fields, with applications actually falling in physics, electricity, and chemistry-related inventions.

Figures 2 through 4 about here

Figure 3 shows the initial response to the introduction of the multi-claim system. This figure shows the number of claims per patent application by section of the International Patent Classification (IPC) System. ${ }^{28}$ This figure illustrates that the number of claims per patent jumped in 1988. The most dramatic increase is seen in section $\mathrm{C}$ (chemistry-related inventions) and section $\mathrm{A}$, which includes pharmaceuticals. General managers in the intellectual property division of pharmaceutical and chemical companies expressed that they were quick to adopt the new system, because they already learned how to utilize the multi-claim system from the more limited multi-claim system introduced in 1976. This feature of the 1976 revision in the patent law had been heavily utilized in patents of chemical compounds. On the other hand, the increase in class $\mathrm{H}$ (electricity-based inventions, which includes semiconductors and computers) and class $\mathrm{G}$ (physics-based inventions, which includes copiers), was more gradual, suggesting a learning process firms patenting in these areas had to go through before they could fully utilize the multiclaim system.

While applications have leveled off or fallen since patent reform, patent grants have followed a 
very different trend. Recall that one implication of the multi-claim system is that in makes the novelty of an invention easier to demonstrate, increasing the likelihood that a patent will eventually be granted. If this effect is real, then we should expect to observe a sharp increase in grants 3-5 years after patent reform (based on the historical lags between file date and grant date). In fact, patent grants exploded in certain technology fields such as physics and electricity, almost tripling between 1991 and 1992. Less extreme increases can be seen in all technology fields. While this increase is consistent with the positive effects ascribed to patent reform, this is, at best, circumstantial evidence which certainly does not constitute proof of the story. A number of other institutional changes - notably an increase in the number of patent examiners and the introduction of the electronic filing and processing system - are likely to have contributed to these changes.

Figure 4 shows trends in intellectual property lawsuits filed in Japan from 1983 through 1995. Patent-related lawsuits are only a component of these sums, but one can observe a striking and sharp upturn in the incidence of lawsuits in the most recent years. ${ }^{29}$ These are the years in which, based on historical lags, we would expect to begin observing grants of patents filed under the new system. ${ }^{30}$ Given the expense of civil litigation in Japan, we would only expect to see an increase if the plaintiffs believed that the likelihood of victory (or the size of damage awards) increased. Unfortunately, we have not yet been able to obtain quantitative data on the outcomes of this kind of civil litigation, but the observed trends suggest patent reform strengthened the position of incumbent patent holders. This is consistent with the perceptions of interviewed firms.

Data used in the empirical analysis. Examining the impact of these reforms at the micro level requires data on patenting, $\mathrm{R} \& \mathrm{D}$, and other firm characteristics at the firm level. To undertake such analysis, we constructed an original data set of 307 publicly traded Japanese manufacturing firms, drawn from various industries. The actual number of firms used in our empirical work varies according to specification because data on some variables are not available for all firms in all years. Data on firm sales, capital investment, and industry affiliation are taken from the Japan Development Bank (JDB) Corporate 
Finance Database. This data set also contains information on firms' R\&D spending, but the reliability of this series is not high. These data were therefore supplemented with data on firm-level R\&D expenditures drawn from Japanese language primary sources, especially the Toyo Keizai Kaisha Shiki Ho R\&D survey. ${ }^{31}$ This analysis also requires data on Japanese patenting at the firm level. Regrettably, such data are difficult to obtain and, relative to our U.S. data, extremely expensive. Despite the assistance of the staff of JAPIO, which provides the only practical electronic patent database in Japan, and despite their provision of a generous discount over the rates charged to commercial users, we were only able to obtain two series of patent data for each of our sample firms. First, we have information on the total patent applications in each of our sample years, from 1980 to $1994 .{ }^{32}$ Second, we have a random sample of patent applications taken out up to 300 applications in each year, which includes information on the number of claims each application contained as well as the IPC codes in each patent. Based on that random sample, we can estimate changes in patent quality for the entire stream of the firms' patents.

Ironically, our data on the U.S. patenting of our Japanese firms are much more complete than our Japanese patent data. Initially, we obtained data on U.S. patenting, including complete information on the number of patent classes assigned to each patent, from the CASSIS CD-ROM disk published by the U.S. PTO. These data were matched with the REI patent database in order to obtain information on the number of claims and ex-post citations for each of these patents. ${ }^{33}$

Finally, as a proxy for investment opportunity, we calculated "average Q" for each firm-year in our data set. This calculation was undertaken along the lines of Hoshi and Kashyap (1990). ${ }^{34}$ Further details on data construction are available from the authors on request.

\section{Effects of the 1988 reforms on R\&D}

Empirical framework. Our first empirical examination is to test if the expansion of patent scope in January 1988 was followed by an increase in the level of R\&D investment. While the modeling framework alluded to in section 5 (and fully presented in Appendix 1) captures a number of interesting 
features of reality, the available data are such that it is difficult to directly test such a model. Furthermore, the theoretical results achieved in that framework are generated at the cost of some untenable assumptions: in the real world, firms are not symmetric, profits from particular innovations are not observed nor do we observe the actual outcomes of individual patent races. So, in motivating our empirical work, we utilize the following necessarily simpler framework, which borrows from Cornelli and Schankerman (forthcoming). Let the profits obtained from an innovation be described by

$$
\int_{0}^{T} \pi(w, q, \theta, r) e^{-i T} d t=V
$$

where $\mathrm{T}$ is the length of patent protection, which we presume for the moment to be fixed across all firms and years. ${ }^{35}$ The profit function, $\pi$, gives the period by period flow of profits from innovation. It is assumed to be concave and monotonically increasing in four important parameters. The first, w, represents the scope ("width") of patent protection, which will be common to all firms but vary over time. The next parameter, q, represents expectations of future demand and other "macroeconomic" conditions which effect the future profit streams generated by current investment. $\theta$ represents the research productivity of a firm - the "quality" of its research team. This varies across firms, but is assumed to be constant within firms over time. Finally, the profit function is increasing in $r$, the level of $R \& D$ effort, as higher levels of $R \& D$ investment lead to "better" (more privately - and socially - profitable) innovations.

The firm sets $R \& D$ to maximize profits, earning a profit net of research costs of

$$
\int_{0}^{T} \pi(w, q, \theta, r) e^{-i T} d t-\frac{r^{2}}{2}
$$

We assume quadratic costs of adjustment in R\&D here, but we contend that our qualitative results would carry over for any non-concave cost function. Integration over $\mathrm{T}$ allows us to rewrite the problem as

$$
\underset{r}{\operatorname{Max}} \frac{1}{i} \pi(w, q, \theta, r)\left(1-e^{-i T}\right)-\frac{r^{2}}{2}
$$

The firm's first order condition is 


$$
r=\frac{1}{i}\left(1-e^{-i T}\right) \pi_{r}
$$

Because $\pi$ is assumed to be concave, the second order conditions are satisfied, and by the implicit function theorem there exists a function $\phi$ such that

$$
r^{*}=\phi(w, q, \theta, T)
$$

where $\phi_{w}>0, \phi_{q}>0, \phi_{\theta}>0, \phi_{T}>0$. For the purposes of our empirical analysis, we take a log-linear first order approximation of this $\phi$ function. Our estimating equation thus becomes:

$$
r_{i t}=\beta_{0}+\beta_{1} w_{t}+\beta_{2} q_{i t}+\sum_{c} \delta_{c} D_{c}+\theta_{i}+\varepsilon_{i t}
$$

Here $r$ is the natural $\log$ of $\mathrm{R} \& \mathrm{D}$ spending by firm $i$ in year $t, w$ is an indicator variable taking on a value of 0 in the pre-reform years and a value of 1 thereafter, $q$ is a measure of firm-level "average Q", and $\theta$ is a measure of firm-level research productivity. We add industry dummy variables, $D$, to control for differences in levels of R\&D spending across industries (possibly due to differences in technological opportunity). Although firm-level research productivity is not observed, we can deal with it econometrically by using fixed-effects models and random effects models, depending on what assumptions we wish to make about the correlation of this unobserved productivity with our other independent variables.

Macro disturbances. In essence, our identification comes from common shifts in a time trend. Unfortunately, there are at least four other "macro" shocks, all more or less contemporaneous with patent reform, which could also have had an impact on firms' R\&D effort. The first is the now infamous bubble economy. Starting in 1986-87, the Japanese central bank adopted a fairly loose monetary policy. To the extent that Japanese firms were credit-constrained prior to the onset of the bubble economy, the bubble years could have generated a liquidity-induced increase in R\&D spending that had nothing to do with patent reform. The second is yen appreciation. From 1985 through 1987, the yen appreciated substantially relative to the dollar. Faced with an increase in foreign competition, many Japanese firms sought to defend their global market share through quality-upgrading. To the extent that this was a common reaction, one 
may conclude that "competitive necessity" rather than patent reform, was the mother of any observed increase in Japanese invention. Third, one could argue that "technological opportunity" expanded for Japanese firms in the late 1980s, and that increases in R\&D were driven by this exogenous increase in $R \& D$ productivity rather than any increase in the ability of firms to appropriate the returns from that $R \& D$ through stronger patents. Finally, increasing international "technological competition" between U.S. and Japanese firms might have prompted additional innovation and patenting. ${ }^{36}$ Over the course of the 1980 s, many U.S. firms sought to defend themselves from effective Japanese rivals by suing them for patent infringement in U.S. courts. It is argued that a few well-publicized victories by U.S. incumbent firms prompted Japanese firms to begin "ramping up" their patent portfolios.

Untangling all of these effects is quite difficult given the available data. However, one avenue open to us is to exploit the variation in the cross-section dimension of our data. Our data set includes a number of large, R\&D-intensive firms in technologically progressive industries which held sizable patent portfolios prior to patent reform. Ex ante, we would expect these firms to benefit disproportionately from reform, and hence modify their behavior. Likewise, we can identify subgroups of firms which are more likely to be affected by liquidity constraints, currency appreciations, and other potential confounding effects. By comparing changes within firms over time in $\mathrm{R} \& \mathrm{D}$ and patenting across these groups, we can get some sense of the extent to which observed changes in innovative activity can reasonably be ascribed to patent reform. Alternatively, we can insert control variables which allow us to more precisely identify the impact of patent reform.

In our initial regressions, we do not attempt to completely eliminate the effects of these other "macro" shocks. Therefore, we interpret our initial results as representing an "upper bound" of the real $\mathrm{R} \& \mathrm{D}$ response to patent reform. The expansion of patent rights is represented by a dummy variable, reform, equal to one from 1987 (on the presumption that firms might have begun to alter their behavior even before the law officially went into force). In addition to this dummy variable, we include a general time trend in order to avoid falsely attributing any general tendency for Japanese firms to increase $R \& D$ 
spending over time to patent reform. The time span of this and other regressions is 1980-1994. Finally, in our specifications with the $\log$ of $R \& D$ spending as the dependent variable, we include contemporaneous sales as a measure of firm size. This is intended purely as a control variable.

Thus, our baseline estimating equation becomes

$$
r_{i t}=\beta_{0}+\beta_{1} \text { reform }_{t}+\beta_{2} q_{i t}+\beta_{3} T_{t}+\beta_{4} s_{i t}+\sum_{c} \delta_{c} D_{c}+\theta_{i}+\varepsilon_{i t}
$$

where $r$ is the $\log$ of real R\&D spending of firm $i$ in year $t, q$ is "average Q," $T$ is the time trend, $s$ is the $\log$ of sales, and the other variables are as before. ${ }^{37} \mathrm{Q}$ is used as a control variable for the impact of the bubble economy and, to the extent that the Japanese stock market anticipates it, the impact of changes in "technological opportunity." 38 Results from fixed and random effects versions of this initial specification are given in columns 1 and 2 of Table 2. The estimated coefficient on reform falls between .088 and .089, suggesting that reform led to an increase of R\&D spending on the order of $9 \%$.

Tables 1 through 4 about here

This is a small, but not insubstantial estimate of the impact of patent reform on R\&D spending. However, as we noted, these coefficients represent an upper bound of the effect that could actually be attributed to patent reform. In the empirical specifications which follow, we subject this finding to increasingly stringent robustness checks. We find that these initially strong results tend to fade quickly as we include more controls.

If patent reform is truly driving the observed increase, then we might expect a measure of "technological orientation," based on cumulated patents prior to patent reform, to be positively associated with the $R \& D$ response to patent reform. We construct such a measure by counting the cumulated sum of Japanese patents applied for by all firms in our sample through 1987. We set a dummy variable, patent_intensity, equal to one for all firms with higher than the median number of cumulated patents in this year. We then interact this dummy variable with our "reform" variable, creating an interaction term - 
patent_intensity*reform - which is introduced into columns 4 and 5 of Table 3 . Our empirical specification thus becomes

$r_{i t}=\beta_{0}+\beta_{1}$ reform $_{t}+\beta_{2} q_{i t}+\beta_{3} T_{t}+\beta_{4} s_{i t}+\beta_{5}$ patent_intensity $_{i} *$ reform $_{t}+\sum_{c} \delta_{c} D_{c}+\theta_{i}+\varepsilon_{i t}(8)$

If the post-patent reform increase in $R \& D$ spending was driven primarily by the efforts of firms to respond to changes in appropriability conditions, then we might expect this increase to be disproprotionately higher for more technologically sophisticated firms. Such a disproportionate effect would be indicated by a positive, statistically significant $\beta_{5}$ coefficient. As the reader can see from columns 3 and 4 of Table 2, this measure is negatively correlated with the R\&D response to patent reform in the random effects and fixed effects specifications, calling into question the view that the coefficient on the reform variable in the first two columns is really driven by patent reform.

We also tested the robustness of our initial results by altering the assumed "date" of reform. If one pushes back the date of patent reform by a single year (for instance, if one sets reform=1 in years on or after 1988) the positive "level shift" effect identified in the initial specifications turns negative and loses significance. We also observe a negative effect (albeit statistically insignificant) if we set the reform=1 in years on or after 1990. We can see this clearly in the first two columns of Table 3. On the other hand, dating the reform from earlier years (such as 1985) produces a positive, significant estimate in most specifications, as is illustrated in column 3 of Table 3. This was long before the firms in our sample could have reasonably anticipated patent reform. This sensitivity of our results casts doubt on the view that the observed upturn in $R \& D$ spending is really driven by a one-time response to the implementation of patent reform in 1988.

Exploitation of our industry cross-section did not produce results favorable to the view that patent reform is driving a large component of the observed increase in R\&D. We collapsed our set of industry dummy variables down to eight and interacted them with the reform dummy variables in column 4 of Table 3. The coefficients of these interaction terms and the standard errors are given in that column. ${ }^{39}$ The 
electronics/precision instruments industry cluster comes up consistently negative in all specifications, as does the "chemicals" cluster. This is troubling, given that these clusters are among the most patent and $\mathrm{R} \& \mathrm{D}$ intensive in Japan. ${ }^{40}$ As a further variation on this theme, we tried estimating versions of equation (7) for only the electronics industry and only the pharmaceuticals industry. The results of the "reform" dummy were typically insignificant or negative. ${ }^{41}$

As a final alternative approach, we included as a right hand side variable the average number of claims per patent per firm-year (average_claim). ${ }^{42}$ After all, if the expectation of being able to exploit the patent reforms ex ante is driving up R\&D spending, then one should expect to see a positive relationship between R\&D increases and actual exploitation of the multi-claim patent system ex post. Thus, we could adopt the following specification:

$$
r_{i t}=\beta_{0}+\beta_{1} \text { reform }_{t}+\beta_{2} q_{i t}+\beta_{3} T_{t}+\beta_{4} s_{i t}+\beta_{5} \text { average_claim }_{i t}+\sum_{c} \delta_{c} D_{c}+\theta_{i}+\varepsilon_{i t}
$$

Unfortunately, there is no evidence of this kind of relationship. ${ }^{43}$ Average_claim is consistently negative in random effects and fixed effects specifications, as is illustrated in Table 4. This casts further doubt on the view that it is really patent reform that is responsible for the observed increase in R\&D spending.

The best conclusion that can be drawn from this set of results is that there was a broadly observed increase in $R \& D$ spending in the 1980 s which overlapped in time with the onset of patent reform in Japan. However, much of this increase actually predated the onset of patent reform and robustness checks suggest that relatively little, if any, of the upturn can be reasonably ascribed to the change in Japan's patent regime.

\section{Effects of the 1988 reforms on patenting at the micro level in Japan and the U.S.}

An increase in R\&D effort of any magnitude is only socially beneficial to the extent that it results in increased innovation. We therefore want to test whether or not the innovative output of Japanese firms increased after patent reform. Given the previous results, of course, we will have to be cautious in attributing any observed increase to the effects of patent reform. The standard approach taken in the 
literature has been to estimate a knowledge production function, where some constant fraction of ideas are assumed to be patented, and so, at least for individual firms, there is a stable relationship between patenting and innovation over time.

In the current context, this approach is problematic. The "units" of innovative output have changed as a direct consequence of patent reform, as it is now possible to "repackage" the firms' innovative output into a smaller number of "larger" ("broader") patents. In order to obtain a consistent measure of Japanese innovative output before and after patent reform, we will need measures of patent quality as well as quantity. We use two alternative measures of patent "quality" or "scope." The first is the number of claims per patent. Obviously, since patent reform lifted the constraint on claims per patent, we should observe this increasing over time.

However, the fact that claims were so directly affected by the regime change makes them somewhat suspect as an independent measure of quality. Our discussions with interviewed firms also raised concerns about the use of claims. As we have noted, firms often used multiple claims to describe a single innovation in multiple ways, making it more difficult for rivals to infringe the patent. This defensive use of claims further obscures their reliability as measures of quality. An alternative measure of patent scope, pioneered by Lerner (1994), is to use counts of the number of IPC subclass codes assigned to patents. Lerner has argued that the number of unique IPC codes contained in a patent document is a reasonable proxy for the breadth of technical knowledge embodied in that patent. ${ }^{44}$ We use this count, averaged over a random sample of a firms' patent applications in a given year, as an independent measure of the patent quality of that firm's $t$ th year patent cohort.

If firms respond to patent reform by simply "repackaging" the same number of ideas into a smaller number of patents, then we might expect to observe the number of claims per patent go up, the number of patents go down, and that there is no significant increase in claims-weighted total patent counts. If the total claims-weighted (or IPC subclass-weighted) patent counts increase significantly, this suggests that firms have responded to patent reform with a real increase in innovative output, the necessary but not sufficient 
condition for broader patent rights to be in the public interest.

With only Japanese patents as an index of innovative output, it still might be difficult to distinguish between a real increase in innovative output, and a "cosmetic" increase which represents only firms' rational responses to changes in the patent system. Fortunately, for many of the firms in our sample, we also observe their patenting in the U.S., both prior to and after patent reform. As we have already noted, there were no major reforms in the U.S. patent system at the time of Japanese patent reform, and so there is no incentive for Japanese firms to change their U.S. patenting. However, if Japanese patent reform did indeed induce greater innovation, then some of this might "spill over" into higher levels of U.S. patenting. We will thus examine U.S. patenting, both quantity of grants and the quality of patent cohorts.

The basic empirical specification will be as follows:

$$
p_{i t}=\beta_{0}+\beta_{1} \text { refom }_{i t}+\beta_{2} \log (R \& D)_{i t}+\beta_{3} T_{t}+\sum_{c} \delta_{c} D_{c}+\theta_{i}+\varepsilon_{i t}
$$

where $p$ will be a measure of patent quantity or quality, depending on the specification, for firm $i$ in year $t$, reform is our reform dummy variable, $\log (R \& D)$ is the $\log$ of real $\mathrm{R} \& \mathrm{D}$ spending, and $T$ is the time trend. ${ }^{45}$ A positive, significant coefficient on reform gives us statistical evidence of an increase in innovative output. $\theta$ represents the firm-effect, which we interpret as the research quality of the firm. Again, we include a full set of industry dummy variables or, in some specifications, fixed effects. ${ }^{46}$ We also include "Q" and the log of real sales as additional controls in some specifications.

Tables 5 through 8 about here

Evidence from Japanese patenting. Our first patent results come from regressions using the log of annual counts of Japanese patent applications per firm per year, where the dates are years of application. ${ }^{47}$ We run fixed and random effects models of equation (10). Results are presented in Table 5. We find no statistically significant evidence of a positive "level shift" in the patent data. In fact, the coefficients are negative, although very imprecisely estimated. ${ }^{48}$ Both specifications are consistent with the 
view that, after reforms, Japanese firms' patent applications continued to increase, but at a decreasing rate. In fact, we estimated pre-reform and post-reform time trends separately. A Chow test confirmed the presence of a statistically significant negative trend break in the data.

Though total patent applications failed to increase at the pre-reform rate, total innovative output could have increased substantially if the firms' patent applications contain more ideas. We present two measures of patent scope. The first measure is the number of claims per patent. The second measure is the number of IPC subclasses per patent. Results on claims per patent are presented in Table 6. In these regressions, the cross-section dimension is limited to the subset of firms for which we have claims and class count data. The time series dimension is limited to the years 1983-1994. Using our random sample of Japanese patents per firm, we can actually count the number of claims in these patents. We use this to generate an average number of claims per firm per year, which is the dependent variable in the first two columns of Table 6. In both random and fixed effects specifications, there is a positive, significant level shift in the number of claims per patent at the time of patent reform. In fact, if one weights total patent application counts by the increase in claims per patent, one finds statistically significant evidence of a substantial post-reform increase in "claims-adjusted" total patenting, as is shown in column 3 of Table 6.

On the other hand, there is no evidence that post-reform Japanese patent cohorts contained a larger number of IPC subclasses. Results confirming this are presented in columns 4 and 5 of Table 6 . This holds true regardless of whether one looks at fixed effects or random effects results. It also holds regardless of whether one uses average numbers of classes per patent or total class-weighted patent output as the dependent variable. The absence of any positive shift in this alternative measure of quality suggests that our concerns about claims have some empirical basis. "Claims-adjusted" total patenting may substantially inflate the real increase in innovative output of Japanese firms.

This examination of Japanese patenting at the firm level also provides some insight into how firms have exploited the multi-claim system. The discussion in section 4 noted that claims could be used to "repackage" multiple independent innovations into a single patent document, thereby achieving costs 
savings. Alternatively, overlapping claims could be used "defensively" to more fully appropriate the intellectual product space around a given invention. A careful look at firm-level R\&D series and patent application counts shows that $R \& D$ spending levels have continued to rise while patent application counts have remained stable or fallen. The lack of evidence of a decline in innovative effort suggests that firms are, to some extent, "repackaging" ideas into smaller numbers of patent applications, thereby enjoying some of the potential cost savings. On the other hand, the very different indications that we get from our two alternative measures of Japanese patent quality suggest that many of the claims being inserted in Japanese patent applications are not "independent" ideas, but rather, "overlapping" claims of a defensive nature. Thus, firms seem to be exploiting the potential gains of the new multi-claim system along both potential dimensions.

Evidence from patenting in the U.S. We go through a similar set of regressions with our data on the U.S. patenting of Japanese firms. In the first two columns of Table 7, we present fixed effects and random effects results with the log of total counts of patent grants in the U.S., dated by year of application, as our dependent variable. We find in both cases a significant "level shift" -- there is an increase in U.S. patenting after reforms. The size of the coefficients are quite substantial, they suggest that reform was associated with $40 \%$ higher levels of patenting in the U.S. Given the relatively modest to nil increases in $R \& D$ spending that could be plausibly attributed to patent reform, it seems implausible to think that this increase could be attributed entirely to the effects of patent reform. Robustness checks similar to those conducted in Tables 3 and 4 confirmed this skepticism. It was indeed the more "patent-oriented" firms that were increasing their patenting in the U.S. during this period. ${ }^{49}$ However, attempts to "re-date" reform to, for instance, 1985, also produced statistically significant coefficients of approximately the same magnitude. ${ }^{50}$ The results of the "redating" experiment are shown in columns 3 and 4 of Table 7 . These results suggest that the increased propensity to patent in the U.S. was probably driven by factors other than patent reform. $^{51}$

Moreover, we find little evidence that the scope of Japanese patenting in the U.S. has significantly 
changed. Columns 1 and 2 in Table 8 provide evidence on changes in the number of claims per patent. These columns present results using actual averages of claims per patent per firm per year. There is no significant evidence of an increase in claims per U.S. patent, regardless of whether one uses fixed or random effects. In fact, the estimated coefficient is negative in both cases, albeit statistically indistinguishable from zero.

Columns 3 and 4 in Table 8 present further evidence on changes in the scope of U.S. patents. We were unable to obtain information on the IPC codes assigned to these patents. We were instead forced to count the number of U.S. patent subclasses assigned by the U.S. PTO. For reasons discussed at length in Lerner (1994), this count of classes is much less satisfactory than counts of IPC codes. Nevertheless, we utilize it, with the understanding that there is more "noise" in these counts, and that any inference based on these results must remain tentative. We find no statistically significant evidence of an increase in the number of U.S. patent subclasses per patent, regardless of whether one looks at fixed or random effects estimates.

One test of patent quality in the U.S. remains to be conducted. If Japanese post-reform patents are relatively more "idea-rich," then one might expect them to be more heavily cited by subsequent patents, controlling for the time lag between grant of the cited patent and the lag of the citing patent. ${ }^{52}$ To measure this empirically, we use the "citations function" approach pioneered by Caballero and Jaffe (1993). This approach is described fully in Appendix 2. Results from this specification are given in Table 9. The coefficients for the years 1977-1993 measure the relative "citedness" of the patent cohorts filed in those years. To make these results a bit easier to understand, these coefficients are graphed in Figure 5.

Table 9 and Figure 5 about here

To sum up the results, there is no evident increase in the "citedness" of post-reform patent cohorts. If anything, the post-reform cohorts seem to be less idea-rich than the pre-reform patent cohorts. More research would be required to determine the extent to which "citedness" has really declined, but we can at 
least say that there is no evidence from patent citations of a post-1988 increase in the "quality" of the U.S. patent grants of Japanese firms.

\section{Conclusion}

Does an expansion of patent scope induce additional innovative effort? How responsive are firms to changes in patent design? Answers to these questions are vital in assessing the relevance of the vast theoretical literature on patent design and the appropriateness of current trends in intellectual property rights policy. This paper takes a first step towards providing answers to these questions by examining the response of a large cross-section of Japanese firms to the 1988 patent reforms.

Interviews with firm practitioners revealed that firms recognized the change in the patent law, and that many perceived the reform to have "expanded patent scope" in the sense in which theorists have used this phrase. However, the firms we interviewed perceived their own response to the new law to have been relatively modest, with some interesting exceptions. In addition to providing us with some qualitative sense of firms' responses to the reform, our interviews also drove home the fundamental reality of the substantial heterogeneity in firms' responses to changes in patent systems and the role that organization of the firms' patent operations and its linkage (or lack thereof) to the $R \& D$ department seems to play in explaining this heterogeneity. Exploring the implications of different organizational structures for the impact of patent reform on firm behavior would seem to be a potentially fruitful area for future theoretical research and managerial analysis.

Turning from findings in our small, possibly nonrepresentative sample of interviewed firms to our findings from a fairly large firm level data set, we find statistical evidence of an increase in R\&D spending by Japanese firms that roughly coincided with the onset of patent reform. However, attempts to identify what component of this increase is actually attributable to patent reform suggest that the real partial effect of patent scope expansion on $R \& D$ spending is close to or equal to zero.

Turning to evidence on innovative output, our results are a bit more mixed. We do find evidence of 
an increase in innovative output according to some of our measures. However, we cannot attribute the full amount of this increase to patent reform any more than we can attribute the full observed increase in firms' R\&D spending in the late 1980 s to patent reform. In Japan, where the "units of innovative output" changed as a direct consequence of patent reform, we find a decrease in the rate of growth of patent applications, but post-reform cohorts are more "idea-rich" as measured by claims per patent. On the other hand, there is no evidence whatsoever of an increase in patent quality as measured by the number of IPC subclasses per application. Data on our sample firms' U.S. patent grants provide some support for the conclusion that patenting in the U.S. increased over a period of time which overlapped with patent reform. However, this increase in U.S. patenting evidently pre-dated patent reform by several years, and was therefore likely driven by other factors. There is no evidence whatsoever of any increase in the quality of post-reform U.S. patents, regardless of the measure used. ${ }^{53}$

Japan's patent reforms provide us with a "natural experiment" in patent policy - an expansion of patent scope which took place in an advanced, industrial economy, precisely the sort of economic context in which we might expect such a change to have measurable effects. Nevertheless, the evidence in this paper suggest that Japanese firms have been rather unresponsive to the change in patent regime.

There are two alternative explanations of our findings. One is that firms are responding, but our data do not capture it. We view this as unlikely, given that our data set provides such a rich description of firm innovative inputs and outputs. Our data set covers a fairly large cross-section of firms across a wide range of industries and, the firms and industries most likely to benefit from a strengthening of patent rights are well represented in our data. The other alternative hypothesis is that the 1988 patent reform was actually a very minor change which did not, in fact, significantly change patent scope. As we have already noted at length, this is not consistent with the perceptions of those public and corporate officials who deal with the patent system for a living. Nor does it seem to be consistent with recent trends in intellectual property rights litigation and patent grants, both of which corroborate the opinions of our interviewees.

Obviously, it would be premature to generalize from our findings to all nations or all possible 
patent reforms. In fact, more empirical work on this particular policy experiment in Japan will be necessary before coming to any final conclusions concerning its effects, and we hope that this paper will stimulate additional empirical work in this area. Nevertheless, if correct, our findings may have important implications for the theoretical literature on patent design and for public policies affecting the scope of patent rights. For if stronger patents do not, in fact, effectively induce more innovation, then some of these theoretical models and the "pro-patent" public policies based on them will need to be reexamined. 


\section{Footnotes}

${ }^{1}$ Jeffrey Kushan, who was involved in these negotiations, claims that the U.S. negotiating team never made this argument. Rather, he claims that the U.S. position was quite straightforward: the U.S. wanted to increase the incomes of incumbent U.S. patent holders (and therefore U.S. national income) through stronger global enforcement of patent rights. However, others have defended the U.S. position using the argument given above. See Cockburn and Lanjouw (1998).

${ }^{2}$ There is some work on the value of patent protection derived from surveys of firms. For a recent example of work in this tradition, see Cohen, Nelson, and Walsh (1996). More recently, econometric studies have attempted to quantify the private value of patent protection using patent renewal data. For a recent example of this kind of study, see Schankerman (1998). However, there has been no empirical work, to our knowledge, which tests firms' responses to the significant strengthening of a pre-existing patent regime.

${ }^{3}$ To some extent, this reform represents the first and to date most substantial diplomatic success of the U.S. in imposing stronger patent rights on a major trading partner. The incorporation of the TRIPs agreement into GATT and the successful use of trade sanctions against Brazil to force it to reform its intellectual property rights regime are also important diplomatic successes. See Cockburn and Lanjouw (1998).

${ }^{4}$ This could be important. The Uruguay round of the GATT negotiations required some signatory states to grant patents to pharmaceutical innovations where previously none had existed. Put simply, the absence in these countries of a thriving R\&D intensive pharmaceutical industry to exploit this legal change might make empirical analysis of its effects problematic. Such was not the case with the Japanese reforms.

${ }^{5}$ Two other important differences include the practice of pre-grant disclosure and pre-grant opposition. The former practice has been discussed at length in the literature - see Ordover (1991). It was not affected by patent reform. The pre-grant opposition system was changed to the post-grant opposition system in 1996.

6 "Fusion Systems Corporation in Japan (A)", Harvard Business School, 9-390-021.

${ }^{7}$ In addition, the U.S. system adopts the doctrine of equivalents which states that a product serving the same function as another may infringe its patent. This doctrine had not been explicitly adopted in Japan until the Supreme Court of Japan's ruling on February 24, 1998 on Tsubakimoto Seiko Co. Ltd. vs. THK K.K. (Case No. 1994 (o) 1083).

${ }^{8}$ Another major difference between the U.S. and Japanese patent systems is the existence of a "second tier" intellectual property rights system - the utility model system. When the Japanese patent system was enacted in 1876, the domestic technological level was quite low. To nurture national technological development, Japanese policy makers deemed it necessary to set up a system that protected "minor" inventions which did not fit the patent system. The Japanese Utility Model Law was therefore established in 1896, modeled after the Utility Model Law in Germany. For more details, please consult a longer version of the paper available from the authors.

${ }^{9}$ There were other changes to the Japanese patent system after 1988 which we regard as relatively minor. Changes include the application of the priority-claim system under the Paris Convention to domestic filing, the establishment of the new utility model system, the introduction of the electronic filing, and patent related fee increases. A complete discussion of these changes is given in a longer version of this paper, available from the authors.

${ }^{10}$ Many readers of this popular case study conclude that Mitsubishi Electric did nothing illegal or unfair - it merely exploited a serious mistake made by a competitor unfamiliar with the Japanese patent system. Perhaps not surprisingly, the CEO of Fusion Systems did not see things this way.

${ }^{11}$ Under the Japanese patent system, patent examination is not automatic; an applicant can request the examination within 7 years from the filing date.

${ }^{12}$ This request is dubbed "AP80".

${ }^{13}$ The ideas in this section owe much to discussions with Mark Schankerman and Nancy Gallini, and we thank them for their detailed comments.

${ }^{14}$ Other tools of appropriation include secrecy, "lead time," complementary manufacturing, complementary service, and "other legal means."

${ }^{15}$ Further evidence of the weight Japanese firms place on patents is provided in a very different context in Schankerman (1998). In his study of patent renewals in France, Schankerman finds that Japanese patent holders have a much higher propensity to renew their patent grants than grantees of any other nationality, controlling for 
effects due to technological field. His data examine patents filed from the late 1960s through the early 1980s, suggesting the high degree of "patent consciousness" documented in the survey research of Cohen et. al. was a feature of Japanese firms before patent reform.

${ }^{16}$ Hugh Patrick has suggested to us that obtaining these cost savings was a primary goal of U.S. trade negotiators.

${ }^{17}$ Under the very limited multi-claim systen before the reforms, the average number of claims per patent in 1987 was 1.21 , and so this is not an unrealistic assumption.

${ }^{18}$ We thank Mark Schankerman for suggesting this calculation. This illustration is not quite accurate, as we are using the patent fee schedule from a post reform year to compare the costs of pre-reform and post-reform patent applications. Nevertheless, our basic message here is that the potential costs savings alone could be quite large. As we argue later, however, the expansion of patent scope through this reform was likely to have had even greater impact than cost savings.

${ }^{19}$ As mentioned, our data indicate that claims per patent went from approximately 1 to approximately 4 by 1993 . In principle, a firm could achieve the same level of protection with 10,000 patent applications (each with roughly 4 claims) that would have required 40,000 applications under the old system of one claim per patent. Assuming that filing and examination fees are incurred for all patents, total expenditures would be 1.161 billion yen under the new system, 4.320 billion yen under the old system. Let us further assume that agent fees are incurred on 70 percent of the patent applications. This raises the total costs to approximately 5.39 billion yen under the new system, and a whopping 21.2 billion yen under the old system. Finally, let us assume that firms choose to pay maintenance fees on only twenty percent of their patents (this figure reflects the percentage of patent applications actually granted.) This incurs an additional cost of 3.660 billion yen under the new system and 11.5 billion yen under the old system. The total patent lifetime cost of one year's 10,000 patent applications thus comes to 9.05 billion yen under the new system, 32.7 billion yen under the old. The total cost savings of 23.6 billion yen is equal to $\$ 197$ million. This sum, for instance, is equal to about 9\% of Toshiba's annual R\&D budget in 1993.

${ }^{20}$ Recent trends in patent grants are consistent with this view.

${ }^{21}$ One could expect that, with this "filling up" of the traditionally wide "buffer zone" between patents, provable infringement would become more frequent and intellectual property litigation would increase. We present evidence of a substantial increase in such litigation in Figure 4.

${ }^{22}$ In fact, there is substantial econometric evidence suggesting that the "adjustment costs" associated with R\&D spending are orders of magnitude higher than those associated with physical capital investment (see Himmelberg and Petersen, 1994), which could help explain the muted adjustment to patent reform. Most R\&D spending consists of the salaries of highly specialized research personnel. Building up a strong corporate research team is quite time-consuming, even in the U.S. where the labor markets for such workers are relatively liquid. In Japan, where the lifetime employment system and the relative absence of mid-career hiring places even stronger constraints on the short-run supply of research personnel, these adjustment costs are likely to be higher.

${ }^{23}$ See Nordhaus (1972) and Scherer (1972). However, Nordhaus explicitly recognized the importance of patent breadth, and even gave a parametric representation of it in Nordhaus (1972). He also anticipated the result that narrower patents of longer length could provide the same protection as his "perfectly broad" finitely lived patents.

${ }^{24}$ As we have already noted, the new system provided a higher degree of intellectual property protection than was available under the old system at any price.

${ }^{25}$ This is a particularly important dimension of scope in the U.S., because the U.S. Patent and Trademark Office tends to grant patents more or less automatically if a standard of novelty is met. Often, the actual scope of a patent grant vis-à-vis other overlapping grants is ultimately decided through litigation in the court system after the patent is granted. In contrast, through 1995, the Japanese Patent Office allowed firms to register their opposition to a patent application before that patent was granted, and it used evidence submitted by these firms in deciding whether or not a given patent should be granted. Over the period covered by our data, patent disputes which would have been settled through post-grant litigation in the U.S. were handled within the Japanese Patent Office through the pre-grant opposition process. Thus, this "legal" dimension of patent scope may have been less important in Japan.

${ }^{26}$ The most notable expansion of the ex-post interpretation of the scope of patent claims by the court was the explicit adoption of the doctrine of equivalents by the Supreme Court of Japan in 1998, ten years after patent reform.

${ }^{27}$ For theoretical examinations of the effect of patent protection on sequential innovation, see Green and 
Scotchmer (1995), Chang (1995), Scotchmer (1996) and Cadot and Lippman (1995).

${ }^{28}$ One might argue that the number of claims per patent application might be different from the number of claims per patent granted, but interview results suggests that managers in intellectual property departments do not observe much difference between these two.

${ }^{29}$ We have not yet been able to obtain quantitative data which breaks down filed lawsuits by the kind of intellectual property dispute.

${ }^{30}$ The reader will recall that rivals can only be sued for infringement after a patent has already been granted.

${ }^{31}$ Though these R\&D data are the best publicly available, there are a number of firm-years in which survey data from Kaisha Shiki Ho are not available.

${ }^{32}$ It is important to note that our inference on Japanese patenting is based on data on Japanese patent applications, not Japanese patent grants. In contrast, our data on the U.S. patenting of Japanese firms is based on their patent grants, though these grants have been "re-dated" by date of application. This is primarily due to data availability, as the U.S. PTO does not keep data on unsuccessful applications whereas JAPIO's data on patent grants is much more limited than its data on applications. One fortunate consequence of working with Japanese applications data is that we are not constrained by the historically long and variable lags between application date and grant date in the Japanese system.

${ }^{33}$ The REI data base is further described in Jaffe and Trajtenberg (1997).

${ }^{34}$ We note that the Q-ratio used in this paper is not tax-adjusted. Because of the measurement error induced by this computational shortcut, we do not view the coefficient on the $\mathrm{Q}$ variable as a structural parameter of interest. Hoshi and Kashyap (1990) noted, however, that both tax-unadjusted and tax-adjusted Q ratios follow the same trend.

${ }^{35}$ For simplicity, this formulation is made in terms of a single innovation, but we interpret this as the discounted value of profits from the multiple innovations created by a firm's research program over the course of a given year.

${ }^{36}$ We thank Wesley Cohen for bringing this point to our attention.

${ }^{37} \mathrm{We}$ also estimated versions of (7) with an R\&D/Sales ratio on the left hand side, obtaining qualitatively similar results to those reported here.

${ }^{38}$ Of course, to the extent that the Japanese stock market drove up the prices of Japanese stocks in response to anticipated profits from stronger patent rights, the Q variable might actually absorb some of the impact of patent reform on R\&D spending.

39 This specification, equation (8), and equation (9) were re-run with a full set of time dummies to control for macroeconomic shocks and other time effects. We obtained results that are qualitatively very similar to those presented here.

${ }^{40}$ Electronics is also one of the most export-intensive industries along with the machinery industry and the transportation equipment industry. This and other specifications seemed to indicate that yen appreciation was not an important factor in motivating the observed increase in R\&D spending.

${ }^{41}$ These results suggest that any positive response of pharmaceuticals firms to the extension of patent length was small to nonexistent. One institutional factor which might explain this is the national health care system in Japan. The pricing policies for pharmaceuticals under this system tend to prevent Japanese drug companies from appropriating the full value of their patented innovations.

${ }^{42}$ We thank Marvin Lieberman for suggesting this specification.

${ }^{43}$ We also experimented with versions of (9) in which $R \& D$ spending in year $t$ was regressed on measures of the "average_claim" variable taken from later years. These alternative specifications yielded qualitatively similar results.

${ }^{44}$ See Lerner (1994) for a convincing argument as to why this measure is a reasonable proxy for the scope of patents.

${ }^{45}$ Here "reform" is dated as 1988 , because it was, of course, impossible to file multi-claim patents before then.

${ }^{46}$ Rather than estimate a "shift" change in patenting, we also looked for "trend breaks" in the data by conducting Chow tests for significant differences in pre- and post reform patent trends. This alternative approach yielded qualitatively similar results.

${ }^{47}$ Since the log of zero is undefined, we follow the practice in this literature of taking the log of one plus the actual number of patent applications. This practice is followed in subsequent specifications as well.

48 As a robustness check, we estimated nonlinear "count data" models (Poisson and Negative Binomial 
specifications) as an alternative to the log-linear results presented herein. We obtained qualitatively similar results to those reported here.

${ }^{49}$ However, we found no statistical relationship between the use of the multi-claim system in Japan and the propensity to patent in the U.S. This casts doubt on the view that the increase in U.S. patenting by Japanese firms was driven primarily by the introduction of the multi-claim system. The results of this and other robustness checks are available from the authors upon request.

${ }^{50}$ One factor which does not seem to have contributed to higher propensities to patent in the U.S. was the 1988 "patent process amendment" enacted into U.S. law, which provided U.S. firms with the right to impound imports of goods manufactured abroad using processes which infringed on U.S. patents. We specifically asked our Japanese interviewees about the impact of this legal change, and they indicated that it was not a factor in their decision to patent in the U.S. We nevertheless thank Jeffrey Kushan for calling this procedural change to our attention.

${ }^{51}$ One alternative explanation for the observed increase of patenting by Japanese firms in the U.S., suggested to us by Wesley Cohen, is that it was prompted by a series of high-profile lawsuits in the mid 1980s in which U.S. firms (notably Texas Instruments) successfully sued Japanese firms for patent infringement. Japanese firms are alleged to have responded by "ramping up" their U.S. patent portfolios. In the absence of quantitative data on litigation against Japanese firms in the U.S., this hypothesis is difficult to test formally.

${ }^{52}$ This approach is not available to us with the Japanese data due to the absence of reliable citations data.

${ }^{53}$ One possible reason suggested by our interviews is, again, organizational structure. Japanese firms typically contract the generation of most of their overseas patent documents to foreign patent agents. This organizational disconnect could conceivably lessen the impact of an increase in Japanese innovation on the "quality" of their U.S. patents. 
Figure 1. The "Improved" Multi-claim System

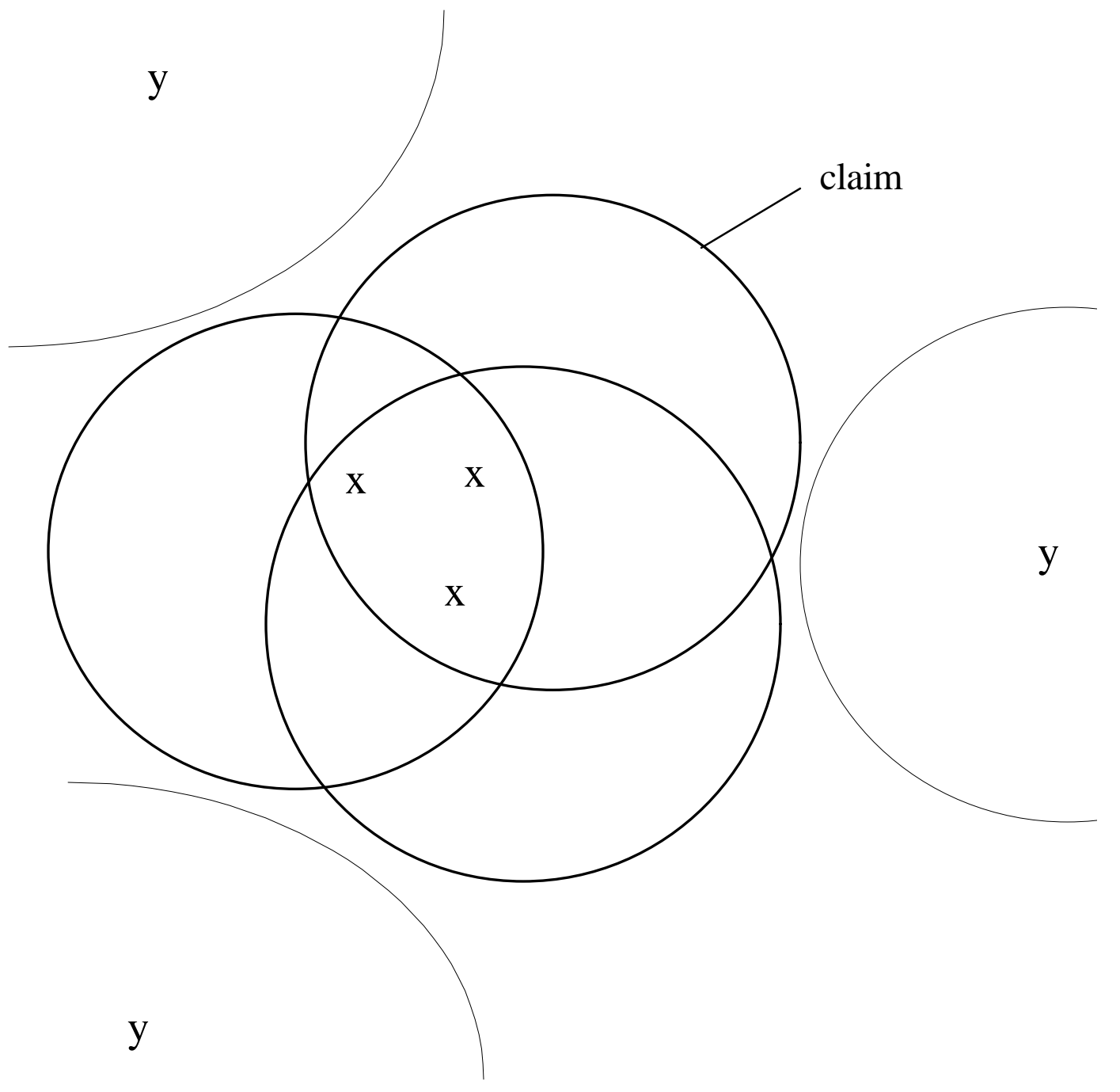

$\mathrm{x}$ : invention by this firm

$\mathrm{y}$ : invention by other firms 
Figure 2. Patent Applications in Japan

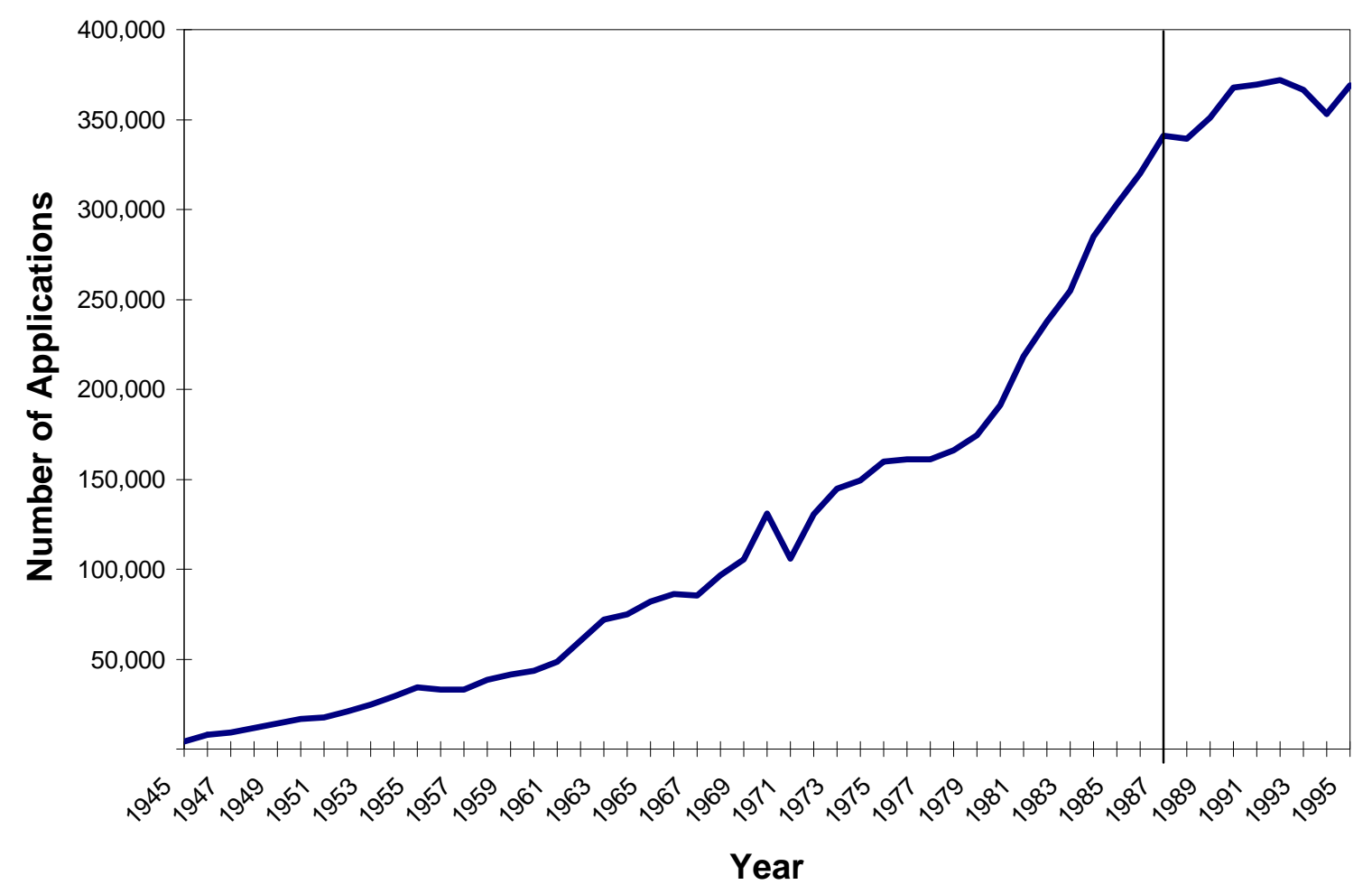

Data source: Japanese Patent Office. 
Figure 3. Number of Claims per Patent Application

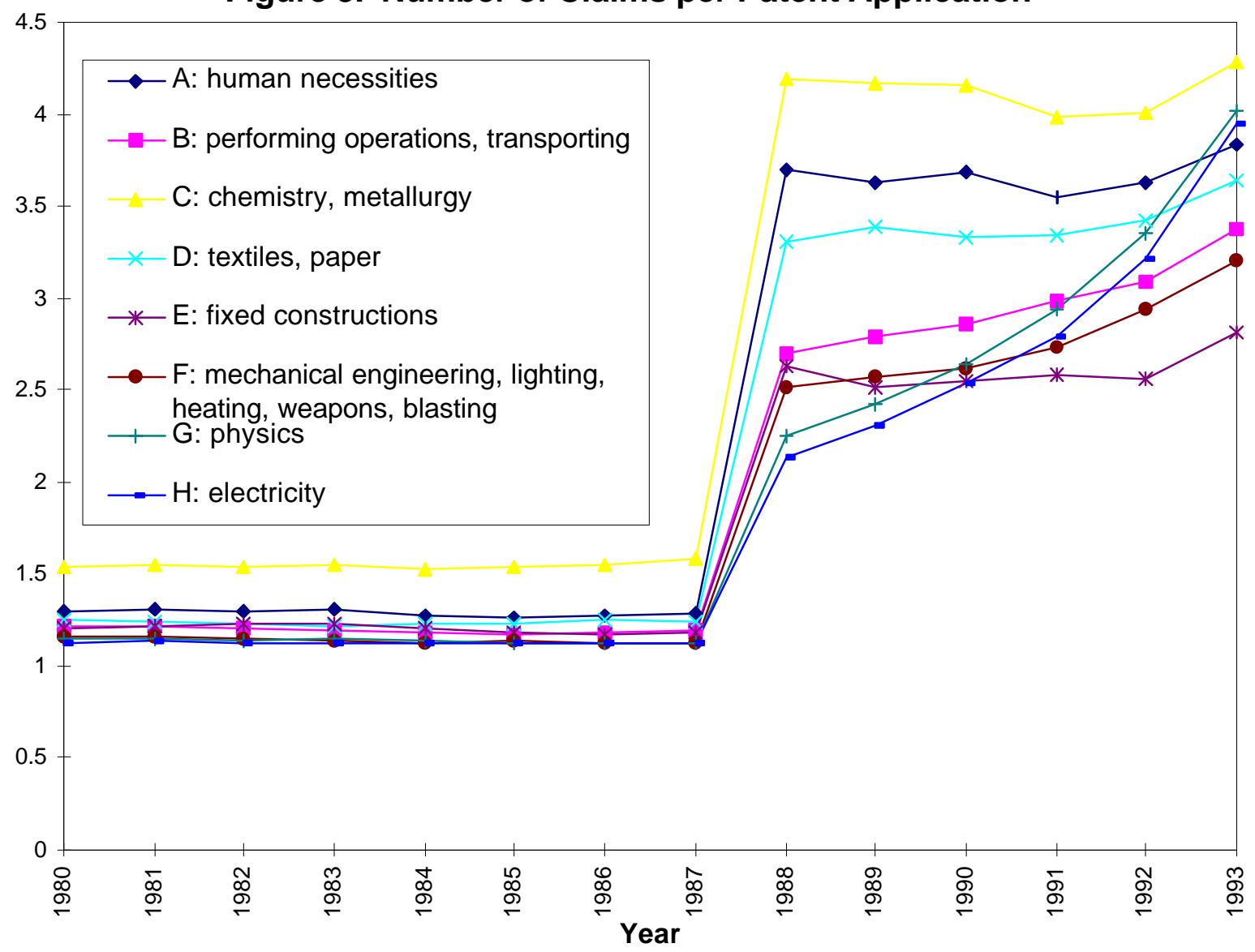

Data source: Japanese Patent Office. The number of claims per patent application to the Japanese Patent Office, by section of the International Patent Classification System. 


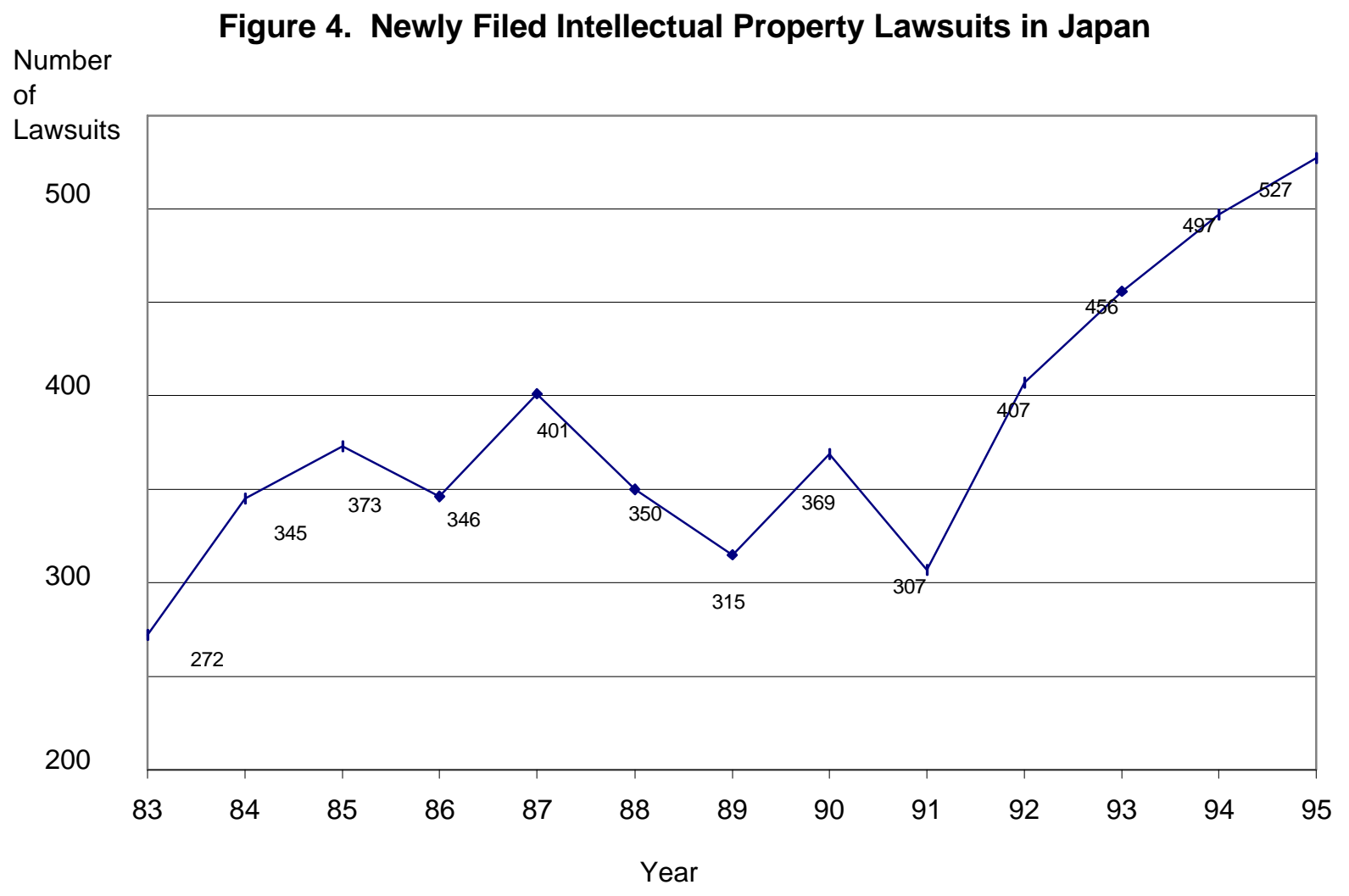

Data source: Industrial Research Institute (1996). 
Figure 5 Quality of Japanese Patent Grant Cohorts as Measured by Subsequent Patent Citations

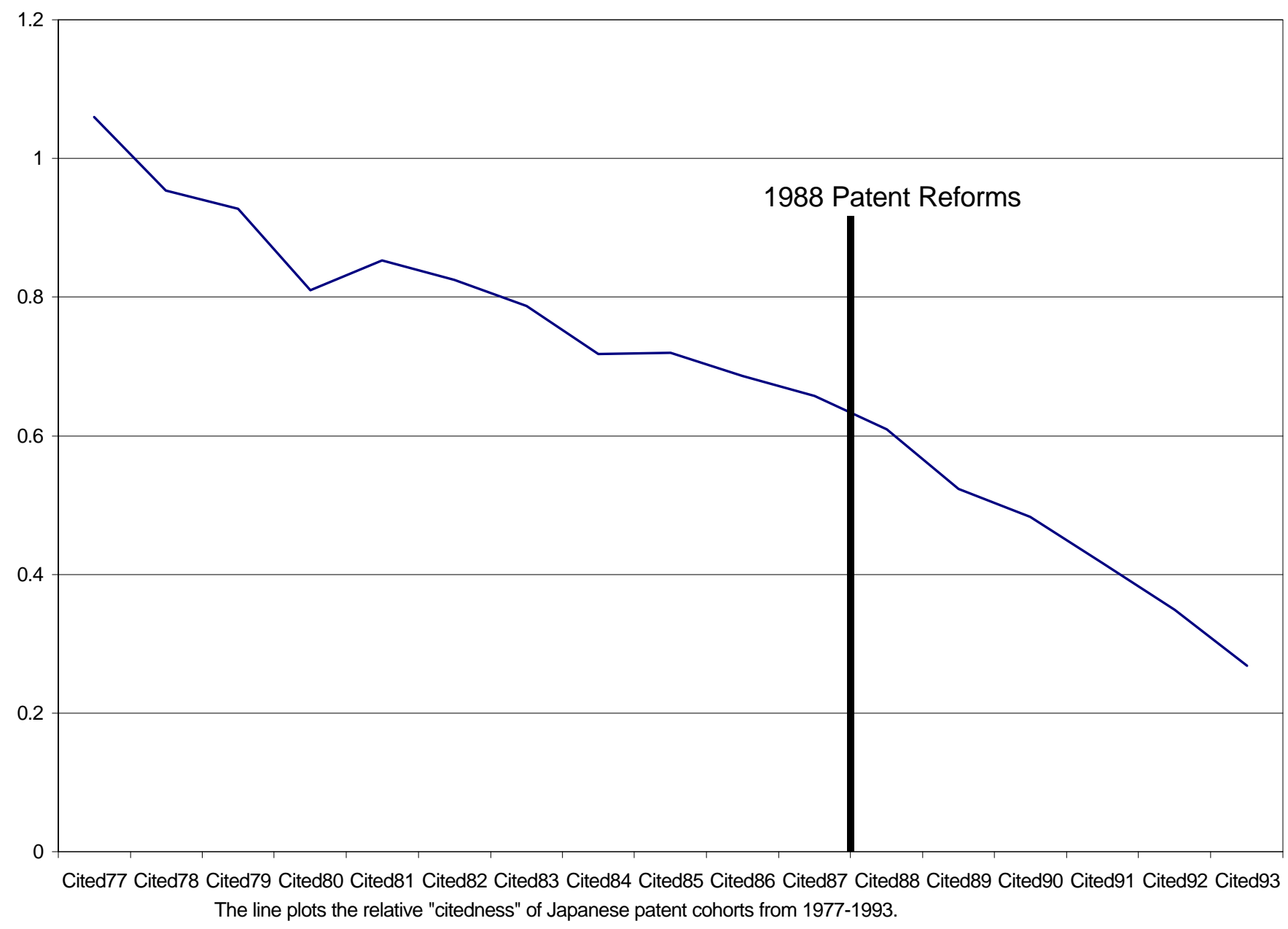


Table 1. Summary Statistics

\begin{tabular}{|c|c|c|c|c|c|}
\hline Variable & ervations & Mean & Std. Dev. & Minimum & Maximum \\
\hline Real R\&D (million yen) ${ }^{1}$ & 3562 & 17211.01 & 43943.79 & 0 & 445212.3 \\
\hline Real sales (million yen) & 4696 & 316383.8 & 640490 & 1673.111 & 9025592 \\
\hline $\mathrm{R} \& \mathrm{D} / \mathrm{sales}$ & 4699 & .034 & .031 & 0 & .178 \\
\hline Counts of Japanese patents & 5073 & 756.158 & 2668.701 & 0 & 34334 \\
\hline Counts of claims per Japanese patent ${ }^{2}$ & 1114 & 2.116 & 1.342 & 1 & 12.740 \\
\hline Counts of classes per Japanese patent ${ }^{2}$ & 1114 & 1.491 & .200 & 1 & 2.333 \\
\hline Counts of US patents & 4896 & 44.434 & 171.224 & 0 & 4302 \\
\hline $\begin{array}{l}\text { Counts of claims per US patent } \\
64\end{array}$ & 4867 & 6.865 & \multicolumn{2}{|c|}{5.725} & 0 \\
\hline $\begin{array}{l}\text { Counts of classes per US patent } \\
7\end{array}$ & 4896 & 1.489 & \multicolumn{2}{|c|}{1.065} & 0 \\
\hline Tobin's Q (average Q) & 4605 & 2.174 & 1.454 & 0.026 & 14.313 \\
\hline Patent citations ${ }^{3}$ & 9605 & 112.118 & 574.115 & 0 & 9106 \\
\hline
\end{tabular}

Note:

1. Data from Kaisha Shiki Ho, high quality R\&D data.

2. Counts of claims and classes per Japanese patent are calculated from a random sample of a firms patent applications in year $\mathrm{t}$. The numbers in our data base are average counts of claims and classes per firm-year.

3. Data on patent citations are drawn from the REI data base at Case Western Reserve University. The citations data are not sorted by firm-year, but by patent characteristics, so that the number of observations differs substantially from our other variables. 
Table 2: The Impact of Patent Reform on R\&D Spending

Dependent variable: $\log$ (real R\&D spending), standard errors in parentheses

\begin{tabular}{|c|c|c|c|c|}
\hline & $\begin{array}{l}\text { (1) Random } \\
\text { Effect }\end{array}$ & $\begin{array}{l}\text { (2) Fixed } \\
\text { Effect }\end{array}$ & $\begin{array}{l}\text { (3) Random Effect } \\
\text { with } \\
\text { Patent_intensity }\end{array}$ & $\begin{array}{l}\text { (4) Fixed Effect } \\
\text { with } \\
\text { Patent_intensity }\end{array}$ \\
\hline Reform & $\begin{array}{c}.089 \\
(.028)\end{array}$ & $\begin{array}{c}.088 \\
(.027)\end{array}$ & $\begin{array}{c}.120 \\
(.033)\end{array}$ & $\begin{array}{c}.143 \\
(.040)\end{array}$ \\
\hline Q & $\begin{array}{l}.0299 \\
(.008)\end{array}$ & $\begin{array}{c}.026 \\
(.008)\end{array}$ & $\begin{array}{c}.031 \\
(.008)\end{array}$ & $\begin{array}{c}.027 \\
(.008)\end{array}$ \\
\hline Time trend & $\begin{array}{c}.019 \\
(.004)\end{array}$ & $\begin{array}{c}.039 \\
(.004)\end{array}$ & $\begin{array}{l}.019 \\
(.004)\end{array}$ & $\begin{array}{c}.039 \\
(.004)\end{array}$ \\
\hline Log(sales) & $\begin{array}{c}.954 \\
(.025)\end{array}$ & $\begin{array}{c}.557 \\
(.040)\end{array}$ & $\begin{array}{l}.966 \\
(.025)\end{array}$ & $\begin{array}{c}.562 \\
(.040)\end{array}$ \\
\hline Patent_intensity*reform & & & $\begin{array}{l}-.054 \\
(.029)\end{array}$ & $\begin{array}{l}-.096 \\
(.018)\end{array}$ \\
\hline Food & $\begin{array}{l}-1.15 \\
(.224)\end{array}$ & & $\begin{array}{l}-1.16 \\
(.220)\end{array}$ & \\
\hline Textiles & $\begin{array}{l}-.931 \\
(.184)\end{array}$ & & $\begin{array}{l}-.940 \\
(.181)\end{array}$ & \\
\hline Paper & $\begin{array}{l}-1.47 \\
(.368)\end{array}$ & & $\begin{array}{l}-1.49 \\
(.362)\end{array}$ & \\
\hline Chemicals & $\begin{array}{l}-.071 \\
(.103)\end{array}$ & & $\begin{array}{l}-.072 \\
(.101)\end{array}$ & \\
\hline Petroleum & $\begin{array}{l}-2.51 \\
(.255)\end{array}$ & & $\begin{array}{l}-2.54 \\
(.2510\end{array}$ & \\
\hline Ceramics, materials & $\begin{array}{l}-.804 \\
(.221)\end{array}$ & & $\begin{array}{l}-.808 \\
(.217)\end{array}$ & \\
\hline Iron/steel & $\begin{array}{l}-.822 \\
(.206)\end{array}$ & & $\begin{array}{l}-.832 \\
(.202)\end{array}$ & \\
\hline Nonferrous metals & $\begin{array}{l}-.975 \\
(.176)\end{array}$ & & $\begin{array}{l}-.974 \\
(.173)\end{array}$ & \\
\hline Fabricated metal products & $\begin{array}{l}-2.31 \\
(.256)\end{array}$ & & $\begin{array}{l}-2.32 \\
(.252)\end{array}$ & \\
\hline Machinery & $\begin{array}{l}-.817 \\
(.126)\end{array}$ & & $\begin{array}{l}-.819 \\
(.124)\end{array}$ & \\
\hline Transportation equipment & $\begin{array}{l}-.317 \\
(.157)\end{array}$ & & $\begin{array}{l}-.328 \\
(.154)\end{array}$ & \\
\hline Precision instruments & $\begin{array}{c}.208 \\
(.266)\end{array}$ & & $\begin{array}{c}.211 \\
(.261)\end{array}$ & \\
\hline Miscellaneous manufacturing & $\begin{array}{l}-1.31 \\
(.373)\end{array}$ & & $\begin{array}{l}-1.33 \\
(.367)\end{array}$ & \\
\hline Engineering & $\begin{array}{l}-1.31 \\
(.624)\end{array}$ & & $\begin{array}{l}-1.31 \\
(.613)\end{array}$ & \\
\hline Constant & $\begin{array}{l}-2.80 \\
(.290)\end{array}$ & $\begin{array}{c}1.38 \\
(.453)\end{array}$ & $\begin{array}{l}-2.94 \\
(.291)\end{array}$ & $\begin{array}{c}1.31 \\
(.453)\end{array}$ \\
\hline Number of observations & 3404 & 3404 & 3404 & 3404 \\
\hline
\end{tabular}

The reference industry is electronics. 
Table 3: The Impact of Patent Reform on R\&D Spending: Robustness Tests Dependent variable: $\log ($ real R\&D spending), standard errors in parentheses

\begin{tabular}{|c|c|c|c|c|}
\hline & $\begin{array}{l}\text { (1) Reform } \\
\text { Begins in } \\
\text { 1988, Fixed } \\
\text { Effect }\end{array}$ & $\begin{array}{l}\text { (2) Reform } \\
\text { Begins in } \\
\text { 1990, Fixed } \\
\text { Effect }\end{array}$ & $\begin{array}{c}\text { (3) Reform } \\
\text { Begins in 1985, } \\
\text { Random Effect }\end{array}$ & $\begin{array}{c}\text { (4) Allowing } \\
\text { Reform Impact to } \\
\text { Vary by Industry, } \\
\text { Random Effect }\end{array}$ \\
\hline Reform & & & & $\begin{array}{c}.344 \\
(.062)\end{array}$ \\
\hline Reform begins in 1988 & $\begin{array}{l}-.051 \\
(.027)\end{array}$ & & & \\
\hline Reform begins in 1990 & & $\begin{array}{l}-.049 \\
(.025)\end{array}$ & & \\
\hline Reform begins in 1985 & & & $\begin{array}{l}.167 \\
(.026)\end{array}$ & \\
\hline Q & $\begin{array}{c}.037 \\
(.008)\end{array}$ & $\begin{array}{l}.031 \\
(.008)\end{array}$ & $\begin{array}{l}.022 \\
(.008)\end{array}$ & $\begin{array}{c}.020 \\
(.008)\end{array}$ \\
\hline Time trend & $\begin{array}{l}.055 \\
(.004)\end{array}$ & $\begin{array}{c}.054 \\
(.004)\end{array}$ & $\begin{array}{c}.016 \\
(.003)\end{array}$ & $\begin{array}{c}.021 \\
(.004)\end{array}$ \\
\hline $\log ($ sales $)$ & $\begin{array}{c}.551 \\
(.040)\end{array}$ & $\begin{array}{l}.553 \\
(.040)\end{array}$ & $\begin{array}{l}.937 \\
(.026)\end{array}$ & $\begin{array}{c}.923 \\
(.028)\end{array}$ \\
\hline Electronics, prec. instruments*reform & & & & $\begin{array}{l}-.445 \\
(.066)\end{array}$ \\
\hline Chemicals, petroleum*reform & & & & $\begin{array}{l}-.236 \\
(.063)\end{array}$ \\
\hline Ceramics, materials*reform & & & & $\begin{array}{l}-.090 \\
(.105)\end{array}$ \\
\hline Steel, nonferrous metals*reform & & & & $\begin{array}{l}-.197 \\
(.077)\end{array}$ \\
\hline Fab. Metal prod., machinery*reform & & & & $\begin{array}{l}-.208 \\
(.069)\end{array}$ \\
\hline Transportation equipment*reform & & & & $\begin{array}{l}-.152 \\
(.077)\end{array}$ \\
\hline Misc. manufacturing*reform & & & & $\begin{array}{l}.129 \\
(.156)\end{array}$ \\
\hline Industry dummies & N.A. & N.A. & $\begin{array}{c}\text { Jointly } \\
\text { significant at } \\
\text { the } 1 \% \text { level }\end{array}$ & $\begin{array}{c}\text { Jointly significant } \\
\text { at the } 1 \% \text { level }\end{array}$ \\
\hline Constant & $\begin{array}{l}1.38 \\
(.454)\end{array}$ & $\begin{array}{c}1.37 \\
(.454)\end{array}$ & $\begin{array}{l}-2.61 \\
(.292)\end{array}$ & $\begin{array}{l}-3.66 \\
(.359)\end{array}$ \\
\hline Number of observations & 3404 & 3404 & 3404 & 3404 \\
\hline
\end{tabular}

The reference sector is "basic manufacturing" (food, textiles, and paper). 
Table 4: The Impact of Patent Reform on R\&D Spending:

Using Average Claims per Patent as a Control Variable

Dependent variable: $\log ($ real R\&D spending), standard errors in parentheses

\begin{tabular}{l|cc}
\hline & (1) Random Effect & (2) Fixed Effect \\
\hline Reform & $\mathbf{. 0 7 7}$ & $\mathbf{. 0 7 2}$ \\
Average_claim & $\mathbf{( . 0 4 2 )}$ & $\mathbf{( . 0 4 1 )}$ \\
& $\mathbf{. 0 2 3}$ & $\mathbf{. 0 3 4}$ \\
Log(sales) & $\mathbf{( . 0 1 5 )}$ & $\mathbf{( . 0 1 5 )}$ \\
& .968 & .513 \\
Q & $(.036)$ & $(.070)$ \\
& .020 & .020 \\
Time trend & $(.012)$ & $(.012)$ \\
& .019 & .044 \\
Industry dummies & $(.008)$ & $(.008)$ \\
Constant & Jointly significant at the $1 \%$ level & N.A. \\
& -2.54 & 2.69 \\
Number of observations & $(.451)$ & $(.860)$ \\
\hline
\end{tabular}


Table 5: The Impact of Patent Reform on Counts of Japanese Patent Applications

Dependent variable: $\log ($ counts of Japanese patent applications), standard errors in parentheses

\begin{tabular}{l|cc}
\hline \multicolumn{1}{l}{ Reform } & (1) Random Effect & (2) Fixed Effect \\
& $\mathbf{- . 0 1 9}$ & $\mathbf{- . 0 2 4}$ \\
$\operatorname{(.029)}$ & $\mathbf{( . 0 2 7 )}$ \\
& .216 & .116 \\
& $(.017)$ & $(.017)$ \\
Time trend & .018 & .027 \\
& $(.004)$ & $(.004)$ \\
Industry dummies & Jointly significant at $1 \%$ level & N.A. \\
Constant & 3.09 & 3.24 \\
& $(.241)$ & $(.135)$ \\
Number of observations & 3535 & 3535 \\
\hline
\end{tabular}


Table 6: The Impact of Patent Reform on Counts of Claims and Classes per Japanese Patent Application

Standard errors in parentheses

\begin{tabular}{|c|c|c|c|c|c|}
\hline & $\begin{array}{l}\text { (1) Average } \\
\text { Counts of } \\
\text { Claims per } \\
\text { Patent, } \\
\text { Random Effect }\end{array}$ & $\begin{array}{l}\text { (2) Average } \\
\text { Counts of } \\
\text { Claims per } \\
\text { Patent, } \\
\text { Fixed Effect }\end{array}$ & $\begin{array}{l}\text { (3) Claims- } \\
\text { Weighted } \\
\text { Total Patents, } \\
\text { Fixed Effects }\end{array}$ & $\begin{array}{l}\text { (4) Average } \\
\text { Counts of } \\
\text { Classes per } \\
\text { Patent, } \\
\text { Random Effect }\end{array}$ & $\begin{array}{l}\text { (5) Average } \\
\text { Counts of } \\
\text { Classes per } \\
\text { Patent, } \\
\text { Fixed Effect }\end{array}$ \\
\hline Reform & $\begin{array}{l}.320 \\
(.095)\end{array}$ & $\begin{array}{c}.315 \\
(.095)\end{array}$ & $\begin{array}{c}.334 \\
(.049)\end{array}$ & $\begin{array}{l}-.037 \\
(.014)\end{array}$ & $\begin{array}{l}-.037 \\
(.014)\end{array}$ \\
\hline $\log (\mathrm{R} \& \mathrm{D})$ & $\begin{array}{l}-.057 \\
(.039)\end{array}$ & $\begin{array}{l}-.261 \\
(.069)\end{array}$ & $\begin{array}{c}.064 \\
(.036)\end{array}$ & $\begin{array}{l}-.010 \\
(.007)\end{array}$ & $\begin{array}{l}-.015 \\
(.011)\end{array}$ \\
\hline Time trend & $\begin{array}{c}.215 \\
(.014)\end{array}$ & $\begin{array}{l}.229 \\
(.014)\end{array}$ & $\begin{array}{c}.101 \\
(.007)\end{array}$ & $\begin{array}{c}.032 \\
(.014)\end{array}$ & $\begin{array}{c}.032 \\
(.002)\end{array}$ \\
\hline $\begin{array}{l}\text { Industry } \\
\text { dummies }\end{array}$ & $\begin{array}{c}\text { Jointly } \\
\text { significant at the } \\
1 \% \text { level }\end{array}$ & N.A. & N.A. & $\begin{array}{c}\text { Jointly } \\
\text { significant at the } \\
1 \% \text { level }\end{array}$ & N.A. \\
\hline Constant & $\begin{array}{c}.507 \\
(.387)\end{array}$ & $\begin{array}{c}2.49 \\
(.630)\end{array}$ & $\begin{array}{c}4.96 \\
(.332)\end{array}$ & $\begin{array}{c}1.27 \\
(.069)\end{array}$ & $\begin{array}{c}1.39 \\
(.095)\end{array}$ \\
\hline $\begin{array}{l}\text { Number of } \\
\text { observations }\end{array}$ & 1085 & 1085 & 1072 & 1085 & 1085 \\
\hline
\end{tabular}

Total counts of patent applications are not available for all firms in all years, hence the number of observations differs in column 3. 
Table 7: The Impact of Patent Reform on Patent Grants in the U.S.

Dependent Variable: $\log ($ counts of Japanese patent grants in the U.S.), standard errors in parentheses

\begin{tabular}{|c|c|c|c|c|}
\hline & $\begin{array}{l}\text { (1) Log of } \\
\text { Total Counts of } \\
\text { Patents, } \\
\text { Random Effect }\end{array}$ & $\begin{array}{l}\text { (2) Log of } \\
\text { Total Counts } \\
\text { of Patents, } \\
\text { Fixed Effect }\end{array}$ & $\begin{array}{c}\text { (3) Effects } \\
\text { Setting Date of } \\
\text { Reform = 1990, } \\
\text { Random Effect }\end{array}$ & $\begin{array}{c}\text { (4) Effects } \\
\text { Setting Date of } \\
\text { Reform = 1985, } \\
\text { Fixed Effect }\end{array}$ \\
\hline Reform & $\begin{array}{c}.402 \\
(.045)\end{array}$ & $\begin{array}{c}.402 \\
(.044)\end{array}$ & & \\
\hline Reform begins in 1990 & & & $\begin{array}{l}-.034 \\
(.042)\end{array}$ & \\
\hline Reform begins in 1985 & & & & $\begin{array}{c}.347 \\
(.041)\end{array}$ \\
\hline $\log (\mathrm{R} \& \mathrm{D})$ & $\begin{array}{c}.466 \\
(.023)\end{array}$ & $\begin{array}{c}.262 \\
(.028)\end{array}$ & $\begin{array}{l}.467 \\
(.023)\end{array}$ & $\begin{array}{c}.214 \\
(.029)\end{array}$ \\
\hline Time trend & $\begin{array}{l}-.034 \\
(.006)\end{array}$ & $\begin{array}{l}-.018 \\
(.006)\end{array}$ & $\begin{array}{c}.014 \\
(.006)\end{array}$ & $\begin{array}{l}.001 \\
(.005)\end{array}$ \\
\hline Industry dummies & $\begin{array}{c}\text { Jointly } \\
\text { significant at } \\
\text { the 5\% level }\end{array}$ & N.A. & $\begin{array}{c}\text { Jointly } \\
\text { significant at the } \\
5 \% \text { level }\end{array}$ & N.A. \\
\hline Constant & $\begin{array}{l}-1.43 \\
(.226)\end{array}$ & $\begin{array}{l}-.044 \\
(.221)\end{array}$ & $\begin{array}{l}-1.58 \\
(.227)\end{array}$ & $\begin{array}{l}.158 \\
(.224)\end{array}$ \\
\hline Number of observations & 3555 & 3555 & 3555 & 3555 \\
\hline
\end{tabular}


Table 8: The Impact of Patent Reform on Patent Quality in the U.S.

Standard errors in parentheses

\begin{tabular}{|c|c|c|c|c|}
\hline & $\begin{array}{l}\text { (1) Average } \\
\text { Counts of } \\
\text { Claims per } \\
\text { Patent, } \\
\text { Random Effect }\end{array}$ & $\begin{array}{l}\text { (2) Average } \\
\text { Counts of } \\
\text { Claims per } \\
\text { Patent, } \\
\text { Fixed Effect }\end{array}$ & $\begin{array}{l}\text { (3) Average } \\
\text { Counts of } \\
\text { Classes per } \\
\text { Patent, } \\
\text { Random Effect }\end{array}$ & $\begin{array}{l}\text { (4) Average } \\
\text { Counts of } \\
\text { Classes per } \\
\text { Patent, } \\
\text { Fixed Effect }\end{array}$ \\
\hline Reform & $\begin{array}{l}. .258 \\
(.282)\end{array}$ & $\begin{array}{c}. .211 \\
(.281)\end{array}$ & $\begin{array}{l}.014 \\
(.053)\end{array}$ & $\begin{array}{c}.012 \\
(.053)\end{array}$ \\
\hline $\log (R \& D)$ & $\begin{array}{l}1.09 \\
(.101)\end{array}$ & $\begin{array}{l}.258 \\
(.179)\end{array}$ & $\begin{array}{l}.198 \\
(.018)\end{array}$ & $\begin{array}{l}.198 \\
(.017)\end{array}$ \\
\hline Time trend & $\begin{array}{l}.088 \\
(.037)\end{array}$ & $\begin{array}{l}.150 \\
(.039)\end{array}$ & $\begin{array}{l}-.013 \\
(.053)\end{array}$ & $\begin{array}{l}-.013 \\
(.007)\end{array}$ \\
\hline $\begin{array}{l}\text { Industry } \\
\text { dummies }\end{array}$ & $\begin{array}{c}\text { Jointly } \\
\text { significant at } \\
\text { the } 5 \% \text { level }\end{array}$ & N.A. & $\begin{array}{c}\text { Jointly } \\
\text { significant at } \\
\text { the } 5 \% \text { level }\end{array}$ & N.A. \\
\hline Constant & $\begin{array}{l}-2.41 \\
(.929)\end{array}$ & $\begin{array}{l}4.45 \\
(1.41)\end{array}$ & $\begin{array}{l}-.082 \\
(.168)\end{array}$ & $\begin{array}{l}.055 \\
(.140)\end{array}$ \\
\hline $\begin{array}{l}\text { Number of } \\
\text { observations }\end{array}$ & 3551 & 3551 & 3555 & 3555 \\
\hline
\end{tabular}


Table 9: Citations Function Estimates

\begin{tabular}{l|ll}
\hline Variable & \multicolumn{1}{l}{ Estimate } & Standard Error \\
\hline Diffusion parameter & 0.423 & 0.014 \\
Obsolescence parameter & 0.0000358 & 3.942 E-6 \\
Relative number of citations to patents filed in 1977 & 1.06 & .124 \\
Relative number of citations to patents filed in 1978 & 0.954 & .114 \\
Relative number of citations to patents filed in 1979 & .927 & .119 \\
Relative number of citations to patents filed in 1980 & .810 & .110 \\
Relative number of citations to patents filed in 1981 & .853 & .114 \\
Relative number of citations to patents filed in 1982 & .825 & .114 \\
Relative number of citations to patents filed in 1983 & .787 & .115 \\
Relative number of citations to patents filed in 1984 & .718 & .112 \\
Relative number of citations to patents filed in 1985 & .720 & .116 \\
Relative number of citations to patents filed in 1986 & .686 & .114 \\
Relative number of citations to patents filed in 1987 & .657 & .113 \\
Relative number of citations to patents filed in 1988 & .609 & .111 \\
Relative number of citations to patents filed in 1989 & .523 & .102 \\
Relative number of citations to patents filed in 1990 & .483 & .099 \\
Relative number of citations to patents filed in 1991 & .416 & .088 \\
Relative number of citations to patents filed in 1992 & .349 & .078 \\
Relative number of citations to patents filed in 1993 & .268 & .069 \\
Citing period 1982-85 & .996 & .095 \\
Citing period 1986-89 & 1.11 & .151 \\
Citing period 1990-94 & 1.21 & .220 \\
& & \\
Number of observations & 9605 & \\
\hline
\end{tabular}

The coefficients for the years 77-93 give the "vintage effects" associated with cohorts of cited patents, as in Jaffe and Trajtenberg (1997). 


\section{Appendix 1. The Model in Section 5.}

The particular framework that we use here borrows heavily Denicolo (1996), which, in turn, is based on Lee and Wilde (1980). We consider a race for a patentable innovation between $\mathrm{n}$ symmetric firms. In this model, both the winner and losers of the patent race get positive profits in the post-innovation equilibrium. The length of the patent is finite, and after the patent has expired, both the winner and losers get the same positive profits. Before the innovation, all firms make zero profit. This assumption is made to simplify the exposition of the model. Our results don't change if we assume all firms make the same positive profits before the innovation.

Each firm $i$ invests in R\&D an amount $x_{i}$ per unit of time; $x_{i}$ is a flow cost that firm $i$ pays until one player succeeds. Assuming an exponential distribution, the probability of being successful at a date $\tau$ prior to date $t$ is $\operatorname{Pr}(\tau \leq t)=1-e^{-h\left(x_{i}\right) t}$, where $h\left(x_{i}\right)$ is the (twice differentiable) hazard function which gives the instantaneous conditional probability of success by firm $i$ as a function of its R\&D expenditure $x_{i}$. A concave hazard function is assumed, that is $h^{\prime}\left(x_{i}\right)>0$ and $h^{\prime \prime}\left(x_{i}\right)<0$.

The payoff function of firm $i$ is the present value of expected profits, net of R\&D costs:

$$
\begin{aligned}
\prod_{i} & =\int_{0}^{\infty} e^{-\left[\sum_{j=1}^{n} h\left(x_{j}\right)+r\right] t}\left[h\left(x_{i}\right) V+X_{-i} L-x_{i}\right] d t \\
& =\frac{h\left(x_{i}\right) V+X_{-i} L-x_{i}}{X_{-i}+h\left(x_{i}\right)+r}
\end{aligned}
$$

where $\mathrm{r}$ is the interest rate, $x_{i}$ is $i$ 's $\mathrm{R} \& \mathrm{D}$ expenditure, $h\left(x_{i}\right)$ is $i$ 's instantaneous probability of innovating, $X_{-i}=\sum_{j \neq 1} h\left(x_{j}\right)$ is the instantaneous probability that one of the $(\mathrm{n}-1)$ rivals of firm $i$ innovates, $\mathrm{V}$ is the present value of the prize accruing to the winner, and $\mathrm{L}$ is the present value of the prize to the losers.

Denoting the length of the patent by $\mathrm{T}$, the prize to the winner is:

$$
V=\int_{0}^{T} \pi_{W} e^{-r t} d t+\int_{T}^{\infty} \pi e^{-r t} d t=\frac{1-e^{-r T}}{r} \pi_{W}+\frac{e^{-r T}}{r} \pi
$$

where $\pi_{W}$ is the flow of profits accruing to the patentee, and $\pi$ is the profit after the patent has expired (the same for all firms). Similarly, the prize to the losers of the $R \& D$ race is:

$$
L=\frac{1-e^{-r T}}{r} \pi_{L}+\frac{e^{-r T}}{r} \pi
$$

where $\pi_{L}$ is the flow of profits accruing to the non-innovating firms when they have no access to the patented innovation. We assume $\pi_{W} \geq \pi \geq \pi_{L}$; the first inequality is strict except for the case of zero patent breadth. This implies $\mathrm{V} \geq \mathrm{L}$ with a strict inequality for a positive patent breadth.

Each firm chooses its $R \& D$ investment to maximize its expected profits (1). The first order condition for a maximum is:

$$
\frac{\partial \Pi_{i}}{\partial x_{i}}=\frac{h^{\prime}\left(x_{i}\right)\left(X_{-i}+r\right) V-X_{-i}-h\left(x_{i}\right)-h^{\prime}\left(x_{i}\right) X_{-i} L+x_{i} h^{\prime}\left(x_{i}\right)-r}{\left\{X_{-i}+h\left(x_{i}\right)+r\right\}^{2}}=0 .
$$

It may be easily checked that the second order condition holds. Since all firms are identical, we look for a symmetric Nash equilibrium where $x_{i}=x$ for all $i$. The numerator of condition (4) then becomes:

$$
(n-1) h(x)(V-L)+r V-\frac{1}{h^{\prime}(x)}\left[n h(x)+r-x h^{\prime}(x)\right]=0 .
$$

Let equilibrium investment be denoted $x^{*}$. Substituting for $\mathrm{V}$ and $\mathrm{L}$ and rearranging (5), we get: 


$$
\frac{1-e^{-r T}}{r}\left[(h-1) h\left(x^{*}\right)\left(\pi_{W}-\pi_{L}\right)+r\left(\pi_{W}-\pi\right)\right]-\frac{n h\left(x^{*}\right)+r}{h^{\prime}\left(x^{*}\right)}+x^{*}+\pi=0 .
$$

Note $x^{*}, \pi_{W}$ and $\pi_{L}$ are functions of the breadth of the patent, which can be denoted as $\mathrm{b}$ (and which is (1

- $\alpha$ ) in Denicolo, 1996). We assume that $\pi_{W}{ }^{\prime}(\mathrm{b})>0$ and $\pi_{L}{ }^{\prime}(\mathrm{b}) \leq 0$.

Differentiating equation (6) with respect to b yields:

$$
\frac{d x^{*}}{d b}=\frac{\frac{1-e^{-r T}}{r}\left[(n-1) h\left(x^{*}\right)\left\{\pi_{W}{ }^{\prime}(b)-\pi_{L}{ }^{\prime}(b)\right\}+r \pi_{W}{ }^{\prime}(b)\right]}{(n-1)-\frac{h^{\prime \prime}\left(x^{*}\right)\left(n h\left(x^{*}\right)+r\right)}{h^{\prime}\left(x^{*}\right)^{2}}-\frac{1-e^{-r T}}{r}(n-1) h^{\prime}\left(x^{*}\right)\left(\pi_{W}-\pi_{L}\right)}
$$

Similarly, differentiating equation (6) with respect to T yields:

$$
\frac{d x^{*}}{d T}=\frac{e^{-r T}\left[(n-1) h\left(x^{*}\right)\left(\pi_{W}-\pi_{L}\right)+r\left(\pi_{W}-\pi\right)\right]}{(n-1)-\frac{h^{\prime \prime}\left(x^{*}\right)\left(n h\left(x^{*}\right)+r\right)}{h^{\prime}\left(x^{*}\right)^{2}}-\frac{1-e^{-r T}}{r}(n-1) h^{\prime}\left(x^{*}\right)\left(\pi_{W}-\pi_{L}\right)}
$$

The numerators are positive in (7) and (8). The denominators of (7) and (8) are the same. Assume that the left-hand side of (6) decreases with $x^{*}$. This requires a stability condition analogous to Lee and Wilde's. From this assumption, differentiating the left-hand side of (6) with respect to $x^{*}$, we get:

$$
(n-1)-\frac{h^{\prime \prime}\left(x^{*}\right)\left(n h\left(x^{*}\right)+r\right)}{h^{\prime}\left(x^{*}\right)^{2}}-\frac{1-e^{-r T}}{r}(n-1) h^{\prime}\left(x^{*}\right)\left(\pi_{W}-\pi_{L}\right)>0 .
$$

Hence $\frac{d x^{*}}{d b}>0$ and $\frac{d x^{*}}{d T}>0$.

The prediction for empirical results is, therefore, we should see positive association between the breadth of patent protection (and the length of the patent protection) and R\&D investment.

\section{Appendix 2. The Caballero-Jaffe-Trajtenberg Citations Function}

We use the framework pioneered by Caballero and Jaffe (1993). In this framework, the likelihood that any particular patent $\mathrm{K}$ granted in year $\mathrm{T}$ will cite some particular previous patent $\mathrm{k}$ granted in year $\mathrm{t}$, $p(k, K)$, is assumed to be determined by the combination of an exponential process by which knowledge diffuses and a second exponential process by which knowledge becomes obsolete. That is,

$$
p(k, K)=\alpha(k, K) \exp \left[-\beta_{1}(T-t)\right]\left[1-\exp \left(-\beta_{2}(T-t)\right)\right]
$$

where $\beta_{1}$ is the rate of obsolescence and $\beta_{2}$ measures the rate of diffusion. Here $\alpha$ measures "level effects" on the probability of citation which are a function of the characteristics of the cited and citing patent cohorts. We refer to the likelihood determined by (10) as the "citation frequency" and the citation frequency as a function of the citation lag (T-t) as a citation function. This general approach was also used in Jaffe and Trajtenberg (1997). ${ }^{54}$

The dependence of the parameter $\alpha$ on $\mathrm{k}$ and $\mathrm{K}$ is meant to indicate that these could be functions of certain attributes of both the cited and citing patents. In their work, Jaffe and Trajtenberg have considered a number of attributes of the cited patent $\mathrm{k}$ that might affect its citation frequency and a number of attributes of the potentially citing patent $\mathrm{K}$ that might affect the citation likelihood. Here, we take a radically simplified version of the Jaffe-Trajtenberg approach. We are really only interested in the extent to which post-reform Japanese patent cohorts are more heavily cited. Therefore, we confine ourselves to estimating effects associated with cited year, citing year, and lag. This is analogous to estimating 
"vintage," time, and age effects in a wage model or hedonic price model. If lag (our "age" effect) entered the model linearly, then it would be impossible to estimate all three effects. Given that lag enters the model non-linearly, all three effects are identified in principle. In practice, a model was used in which citing years are grouped into five year intervals.

Consider now a potentially cited Japanese-invented patent granted in 1985. The expected number of citations that this patent will receive from a particular subsequent Japanese patent cohort (e.g., a Japanese patent granted in 1993) is just the above likelihood times the number of patents in the cohorts that are thereby potential citing and cited patents. In symbols:

$$
E\left[C_{t T}\right]=\left(N_{T}\right)\left(N_{t}\right) \alpha_{t T} \exp \left[-\beta_{1}(T-t)\right]\left[1-\exp \left(-\beta_{2}(T-t)\right)\right]
$$

where $\mathrm{C}_{\mathrm{tT}}$ is the number of citations to the patent cohort of year $\mathrm{t}$ by the patent cohort of subsequent year T. Likewise, $\mathrm{N}_{\mathrm{T}}$ is the number of patents in the citing cohort, and $\mathrm{N}_{\mathrm{t}}$ is the number of patents in the cited cohort. This can be re-expressed as

$$
\frac{E\left(C_{t T}\right)}{\left(N_{T}\right)\left(N_{t}\right)}=\alpha_{t T} \exp \left[-\beta_{1}(T-t)\right]\left[1-\exp \left(-\beta_{2}(T-t)\right)\right]
$$

implying that the equation

$$
c_{t T}=\frac{C_{t T}}{\left(N_{T}\right)\left(N_{t}\right)}=\alpha_{t T} \exp \left[-\beta_{1}(T-t)\right]\left[1-\exp \left(-\beta_{2}(T-t)\right)\right]+\varepsilon_{t T}
$$

can be estimated by non-linear least squares if the error is well-behaved. Here, $\mathrm{c}$ is defined as the estimated probability of a citation occurring between patent cohorts $t$ and $\mathrm{T}$. The data set we used for the estimation of (13) was drawn from the REI patent data base. ${ }^{55}$ It is based on the universe of Japanese patents granted in the U.S., and consists of one observation for each feasible combination of values of $t$ and T. All estimation was carried out including a "base" value for $\beta_{1}$ and $\beta_{2}$, with all other effects estimated relative to a base value of unity. The various "vintage" and "age" effects are included by entering multiplicative parameters, so that the estimating equation looks like

$$
p_{t T}=\alpha_{t} \alpha_{T} \exp \left[-\beta_{1}(T-t)\right]\left[1-\exp \left(-\beta_{2}(T-t)\right)\right]+\varepsilon_{t T}
$$

In this model, unlike the linear case, the null hypothesis of no effect corresponds to parameter values of unity rather than zero. For each effect, one group is omitted from estimation, i.e. its multiplicative parameter is constrained to unity. Thus, the parameter values are interpreted as relative to that base group. The base group for the cited year effects is the 1976 cohort of Japanese patents. The base group for the citing year affects are patents granted in years 1979-1981.

\footnotetext{
${ }^{54}$ The description of the citation function and its interpretation closely follows Jaffe and Trajtenberg (1997).

${ }^{55}$ We thank Adam Jaffe for allowing us access to this data base.
} 


\section{References}

Caballero, R. and Jaffe, A.. "How High Are the Giant's Shoulders?" NBER Macroeconomics Annual, University of Chicago Press, Chicago, IL, 1993.

Cadot, O. and Lippman, S.A. "Barriers to Imitation and the Incentive to Innovate." Working paper No. 434, Western Management Science Institute, University of California, Los Angeles, 1995.

Chang, H.F. "Patent Scope, Antitrust Policy, and Cumulative Innovation.” RAND Journal of Economics, Vol. 26 (1995), pp. 34 - 57.

Cockburn, I. and Lanjouw, J. "Do Patents Matter? Empirical Evidence After GATT." Working paper, 1998.

Cohen, W., Goto, A., Nagata, A.., Nelson, R., Walsh, J. "R\&D Spillovers, Patents and the Incentives to Innovate in Japan and the United States.” Working paper, August 1998.

Cohen, W., Nelson, R., and Walsh, J. “Appropriability Conditions and Why Firms Patent and Why They Do Not in the American Manufacturing Sector.” Working paper, June 1996.

Cornelli, F. and Schankerman, M. "Patent Renewals and R\&D Incentives.” RAND Journal of Economics, forthcoming.

Denicolo, V. "Patent Races and Optimal Patent Breadth and Length." Journal of Industrial Economics, Vol. 44 (1996), pp. 249 - 265.

Gallini, N.T. "Patent Policy and Costly Imitation.” RAND Journal of Economics, Vol. 23 (1992), pp. 52 $-63$.

Gilbert, R. and Shapiro, C. “Optimal Patent Length and Breadth.” RAND Journal of Economics, Vol. 21 (1990), pp. $106-112$.

Green, J. and Scotchmer, S. "On the Division of Profit in Sequential Innovation." RAND Journal of Economics, Vol. 26 (1995), pp. 20 - 33.

Harvard Business School. "Fusion Systems Corporation in Japan (A)." 9-390-021, Harvard Business 
School Publishing, Boston MA, 1990.

Himmelberg, C., and Petersen, B. "R\&D and Internal Finance: A Panel Study of Small Firms in HighTech Industries.” Review of Economics and Statistics, Vol. 78 (1994), pp. 38-51.

Hiraoka, K., Kuzuwa, K., Ukai, K. and Mori, O. Description: The Improved Multi-Claim System and the Extended Patent Protection Period. Association of Invention, Tokyo, Japan, 1988.

Hoshi, T. and Kashyap, A.K. "Evidence on q and Investment for Japanese Firms." Journal of the Japanese and International Economies, Vol. 4 (1990), pp. 371 - 400.

Industrial Research Institute. Research on the Procedures of Lawsuits on Intellectual Property Rights. Tokyo, Japan, 1996.

Jaffe, A. and Trajtenberg, M. "Flows of Knowledge from Universities and Federal Labs: Modeling the Flows of Patent Citations Over Time and Across Institutional and Geographic Boundaries.” NBER Working Paper \#5712, 1997.

Japan Patent Association. Amendment of the Patent Law on the Multi-Claim System: Guideline to Utilize the Multi-Claim System. Patent Committee, the Second Sub-committee, No. 151, Tokyo, Japan, 1988.

Klemperer, P. "How Broad Should the Scope of Patent Protection Be?" RAND Journal of Economics, Vol. 21 (1990), pp. 113 - 130.

Lee, T. and Wilde, L. "Market Structure and Innovation: A Reformulation." Quarterly Journal of Economics, Vol. 93 (1980), pp. 395 - 410.

Lerner, J. "The Importance of Patent Scope: An Empirical Analysis." RAND Journal of Economics, Vol. 25 (1994), pp. 319 - 333.

Matutes, C., Regibeau P. and Rockett, K. "Optimal Patent Design and the Diffusion of Innovations.” RAND Journal of Economics, Vol. 27 (1996), pp. 60 - 83.

Merges, R. P. and Nelson, R. R. “ On Limiting or Encouraging Rivalry in Technical Progress: The Effect of Patent Scope Decisions.” Journal of Economic Behavior and Organization, Vol. 25 (1994), 
pp. 1 - 24 .

Niihara, H. ed. Commentary of the Amended Patent Law. Yuhikaku, Tokyo, Japan, 1987.

Nordhaus, W.D. Invention, Growth, and Welfare: A Theoretical Treatment of Technological Change. MIT Press, Cambridge, MA, 1969.

Nordhaus, W.D. “The Optimum Life of a Patent: Reply.” American Economic Review, Vol. 62 (1972), pp. $428-431$.

Okamaoto, T. et. al. "Total Patent Costs (Filing and Maintenance Costs)." Presented at the $27^{\text {th }}$ Pacific Intellectual Property Association General Meeting in Hiroshima, October 1996.

Ordover, J.A. "A Patent System for Both Diffusion and Exclusion." Journal of Economic Perspectives, Vol. 5 (1991), pp. 43 - 60.

Schankerman, M. "How Valuable is Patent Protection? Estimates by Technology Field." RAND Journal of Economics, Vol. 29 (1998), pp. 77-107.

Scherer, F.M. "Nordhaus' Theory of Optimal Patent Life: A Geometric Reinterpretation.” American Economic Review, Vol. 62 (1972), pp. 422 - 427.

Scotchmer, S. "Protecting Early Innovators: Should Second-Generation Products be Patentable." RAND Journal of Economics, Vol. 27 (1996), pp. 322-331.

Scotchmer, S. and Green, J. "Novelty and Disclosure in Patent Law." RAND Journal of Economics, Vol. 21 (1990), pp. 131 - 147. 